\title{
Hydrogen evolution reaction on Co-Ni core-shell nanoclusters in different sizes: A DFT investigation from geometric structures to \\ electronic structures
}

\author{
Hengyue $\mathrm{Xu}^{*}$
}

*State Key Laboratory of Chemical Oncogenomics, Tsinghua Shenzhen International Graduate School, Tsinghua University, Shenzhen, People's Republic of China.

\section{Corresponding author:}

Hengyue Xu, Email: xuhy21@mails.tsinghua.edu.cn

\section{Graphical abstract}

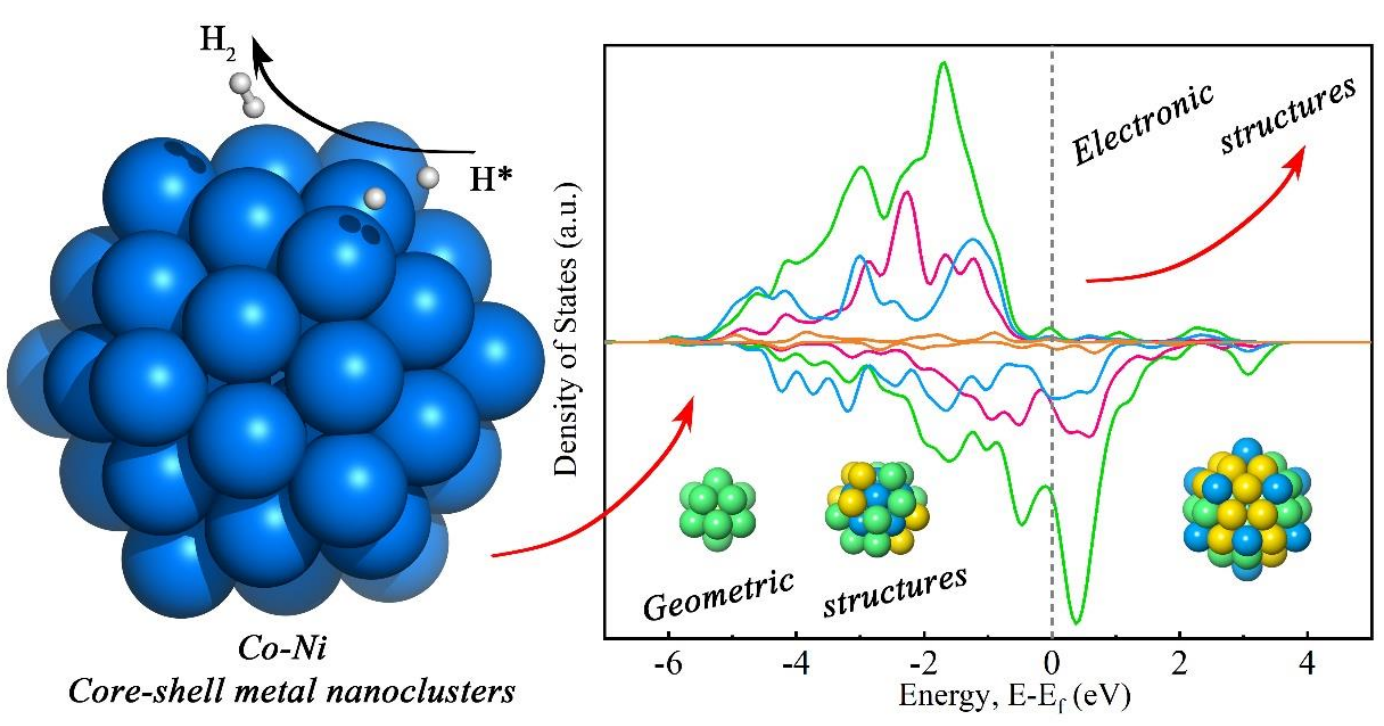




\begin{abstract}
Nanoclusters have broad prospects in the application of hydrogen evolution reaction (HER) electrocatalysis. Its high specific surface area, surface geometry effect, electronic properties, and quantum size effect often make the nanoclusters have higher activity than ordinary electrocatalytic materials. However, it is still challenging to design and regulate nanoclusters and make them have better HER performance. In this work, through first-principle calculations from geometric structures to electronic structures, we try to understand the basic physical and chemical properties and HER performance of nanoclusters composed of transition metals Co and Ni. We optimize the electronic structure and promote effective charge transfer by adjusting the size of nanoclusters and constructing core-shell alloying. First-principle studies reveal that the geometric size and electronic structure of Co-Ni nanoclusters can significantly affect the performance of the hydrogen evolution reaction. We found that $\mathrm{Co} @ \mathrm{Ni}_{12}$ $\left(\left|\Delta \mathrm{G}_{\mathrm{H}^{*}}\right|=0.01 \mathrm{eV}\right)$ shows the best HER performance. The Gibbs free energy of hydrogen adsorption of Co-Ni nanoclusters is positively related to the size of the clusters, and the $\Delta \mathrm{G}_{\mathrm{H}^{*}}$ can be adjusted within a certain range by changing the electronic structure of the clusters. Our research helps to understand and design high-efficiency nanocluster electrocatalysts, paving the way for the rational design and synthesis of advanced electrocatalysts for HER.
\end{abstract}

Keywords: Co-Ni core-shell nanoclusters, Hydrogen evolution reaction (HER), Charge transfer, Electronic and magnetic properties, Catalytic activity, DFT calculation

\title{
INTRODUCTION
}

Since human society entered the industrial revolution, fossil fuels have long dominated the social economy and have become the material basis for human survival and development. However, this dependence is not sustainable. The consumption of a large number of fossil fuels not only leads to an imminent energy crisis, but excessive carbon emissions can also cause serious environmental problems. As a green, efficient, and 
sustainable energy source, hydrogen energy, with its high power density and zero emissions, is expected to replace fossil fuels and become the "green engine" for the operation of human society in the future.

$71 \%$ of the earth's surface is the ocean, which stores huge hydrogen energy. The key to obtaining hydrogen energy from aqueous solutions depends on developing highefficiency electrocatalysts for oxygen evolution reaction (OER) and hydrogen evolution reaction (HER). As we all know, Pt-based materials have high exchange current density and state-of-the-art electrocatalytic performance for hydrogen evolution reactions $(\mathrm{HER})^{1,2}$. Unfortunately, the high cost and scarce reserves have become a stumbling block for the large-scale application of Pt-based materials. Therefore, it remains a critical task to explore and develop new electrode materials with abundant reserves on the earth to replace precious metal electrocatalysts.

From the perspective of electronic structure, in addition to precious metals like Pt, the transition metals $\mathrm{Co}$ and $\mathrm{Ni}$, which are abundant in reserves, also have the potential to serve as hydrogen evolution reactions (HER) catalysts. Co and Ni are $3 \mathrm{~d}$ metals, spinpolarized; the spin-up and spin-down d-bands are shifted with respect to each other. It is relatively easy to form $\mathrm{Co}-\mathrm{H}$ and $\mathrm{Ni}-\mathrm{H}$ bonds for $\mathrm{Co}, \mathrm{Ni}$, and its binary alloy catalysts ${ }^{3}$. At present, alloy materials composed of $\mathrm{Co}$ and $\mathrm{Ni}$ have been proven to have highefficiency HER performance and are expected to replace expensive and scarce Pt-based materials ${ }^{4,5}$. In recent years, nanoscience and nanotechnology have developed rapidly. Compared with traditional bulk electrocatalysts, the nano-sized $\mathrm{Co}$ and $\mathrm{Ni}$ alloy structure not only enhances the HER activity in the synergistic effect ${ }^{6}$ but its high specific surface area, surface geometric effect, electronic properties, and quantum size effect also make it have better HER performance ${ }^{7}$.

Although the current research on Co-Ni nanomaterials has been extensive, there is still a lack of understanding of Co-Ni nanostructures at the atomic level. The relationship between the microscopic geometric structure, electronic structure, and electrocatalytic performance of Co-Ni nanoclusters or nanoparticles is still unclear. Therefore, it is still 
challenging to design Co-Ni nanoscale structures with good performance of HER. In view of the above problems, in order to further understand and design Co-Ni nanoclusters suitable for HER reaction, the geometric structure, thermodynamic stability, charge transfer, chemical activity, electronic, and magnetic properties of 1333- and 55-atoms $\mathrm{Co}$, Ni monometallic nanoclusters and Co-Ni bimetallic core-shell nanoclusters (BCSNCs) were comparatively investigated using density functional theory (DFT) calculations. Furthermore, we also evaluated the performance of these nanoclusters with different geometric structures, sizes, and compositions on the HER reaction. Finally, we found that $\mathrm{Co} @ \mathrm{Ni}_{12}\left(\left|\Delta \mathrm{G}_{\mathrm{H}^{*}}\right|=0.01 \mathrm{eV}\right)$ shows the best HER performance, and the size, composition, and electronic structure of the Co-Ni nanoclusters are potentially related to the $\Delta \mathrm{G}_{\mathrm{H}^{*}}$ of the hydrogen adsorption. The results will help provide a certain theoretical basis and guidance for the controllable synthesis of Co-Ni nanoclusters and the rational design of advanced HER electrocatalysts.

\section{COMPUTATIONAL DETAILS}

All spin-polarized DFT calculations were performed with the Vienna Ab initio simulation package $\left(\mathrm{VASP}^{8}\right)$. The exchange-correlation function was handled using the generalized gradient approximation (GGA) formulated by the Perdew-Burke-Ernzerhof $(\mathrm{PBE})^{9}$. The interaction between the atomic core and electrons was described by the projector augmented wave method ${ }^{10,11}$. The plane-wave basis set energy cutoff was set to $400 \mathrm{eV}$. A $1 \times 1 \times 1 \mathrm{k}$-point mesh for the reciprocal space integration was employed for all the calculations with a discrete character. The periodic boundary conditions were implemented with at least $10 \AA$ vacuum to preclude the interaction between a cluster and its image. The simulation boxes were $15 \times 15 \times 15$ and $20 \times 20 \times 20 \AA$ for 13 -atoms and 55-atoms configurations, respectively. The spin-polarized calculations were performed starting from default values of NIONS $* 1.0$ as the initial magnetic moment for each atom in the VASP code. All structures with a dynamic magnetic moment were fully relaxed to optimize without any restriction until their total energies were converged to $<10^{-6} \mathrm{eV}$, and the average residual forces were $<0.01 \mathrm{eV} / \AA^{12}$. The global transferred 
charge was calculated by the atomic Bader charge analysis ${ }^{13,14}$.

\section{RESULTS AND DISCUSSION}

\section{Co-Ni Core-shell alloyed clusters show similar geometries}

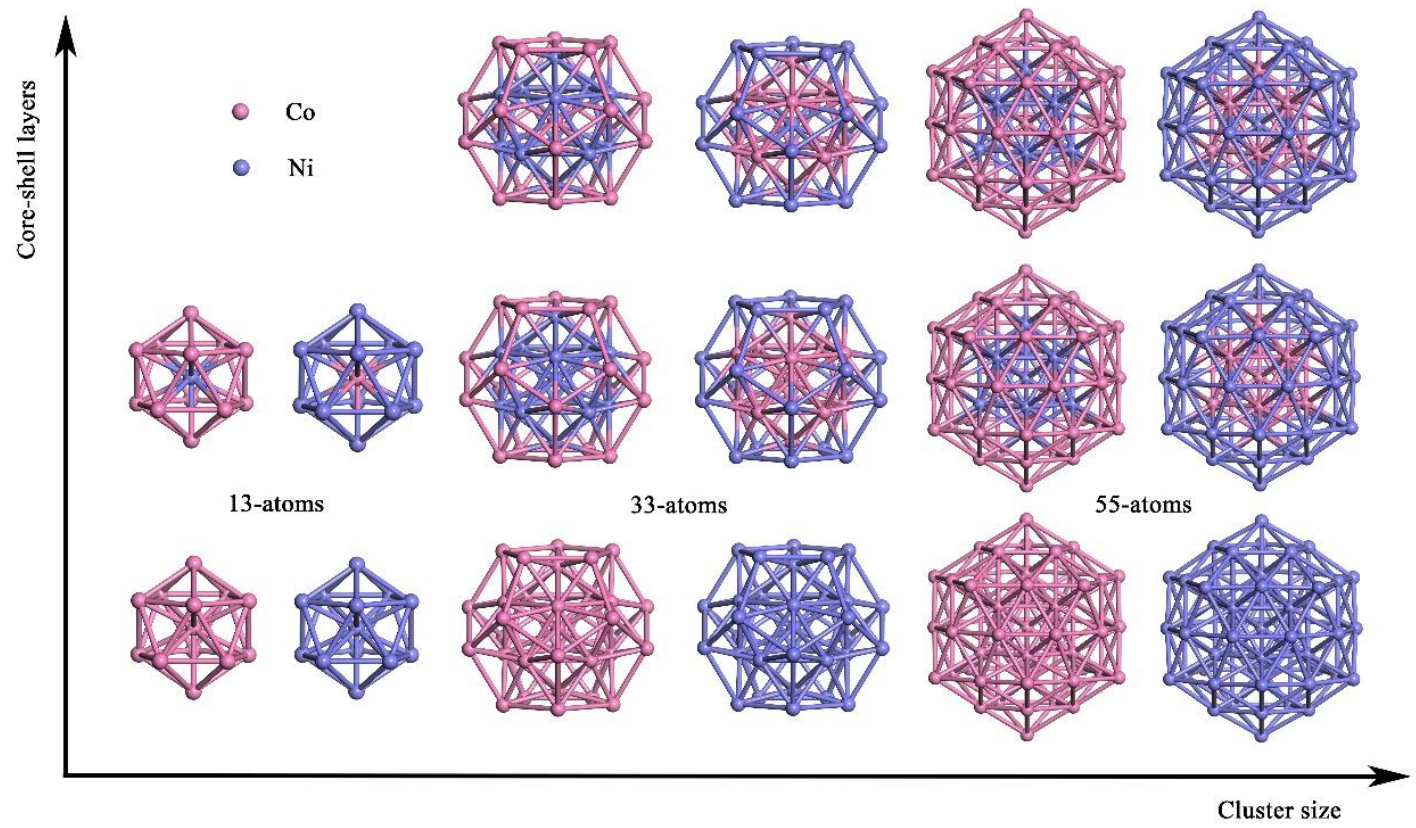

Figure 1 . The geometry structures of 13,33 , and 55-atoms monometallic and bimetallic $\mathrm{Co}-\mathrm{Ni}$ core-shell nanoclusters. Magenta and violet spheres represent $\mathrm{Co}$ and $\mathrm{Ni}$ atoms, respectively.

With spin-polarized DFT calculations, the 13, 33, and 55-atoms monometallic and bimetallic Co-Ni core-shell nanoclusters are displayed in two dimensions of cluster size and the number of core-shell layers, corresponding to the lowest energy. (Figure 1) From the dimension of cluster size, the 13-atoms clusters have an icosahedral geometry structure. The 33-atoms clusters are constructed by adsorbing $20 \mathrm{Co}$ or $\mathrm{Ni}$ atoms on the (111)-shaped surfaces of the 13-atoms clusters, and they show a dodecahedral geometry. Unlike the 33-atoms cluster, the 55-atoms cluster is constructed by adsorbing 42 Co or Ni atoms on 12 vertices and 30 bonds on the 13-atoms cluster, respectively. It shows an icosahedral geometry similar to the 13 -atoms cluster. From the dimension of coreshell layers, 13, 33, and 55-atoms core-shell clusters are constructed by replacing the cluster layers with different elements. Detailed geometric structure analysis data can be 
found in the supporting information. The geometric structure analysis shows that the surface bond length of the 33-atoms Co-Ni clusters is significantly longer than 13 and 55 atoms. Core-shell alloying of clusters can change the bond length of clusters to a certain extent, but their overall structure is not very different.

\section{Ni-surface clusters have higher relative stability than Co-surface}

In order to compare the relative stability of these core-shell nanoclusters, the excess energy $\left(E_{\text {exc }}\right)$ of $\mathrm{A}_{\mathrm{m}} @ \mathrm{~B}_{\mathrm{n}}, \mathrm{B} @ \mathrm{~A}_{\mathrm{m}} @ \mathrm{~B}_{\mathrm{n}-1}$ are defined as follows: ${ }^{15,16}$

$$
E_{\mathrm{exc}}=E_{A_{m} @ B_{n} / B @ A_{m-1} @ B_{n}}-\frac{m}{m+n} E_{A_{(m+n)}}-\frac{n}{m+n} E_{B_{(m+n)}}
$$

$E_{A_{m} @ B_{n} / B @ A_{m} @ B_{n-1}}, E_{A_{(m+n)}}, E_{B_{(m+n)}}$ are the symbols in this formula meaning total energy of monometallic and bimetallic core-shell nanoclusters, A and B with the same size ( $m+n$ atoms) and geometry structures, respectively. In this study, the excess energy $\left(E_{\text {exc }}\right)$ of the monometallic nanoclusters is set to zero as a reference for the corresponding bimetallic nanoclusters benchmark. The negative value of $\left(E_{\text {exc }}\right)$ usually indicates $\left(E_{\text {exc }}\right)$ in general the energetically favorable configuration.
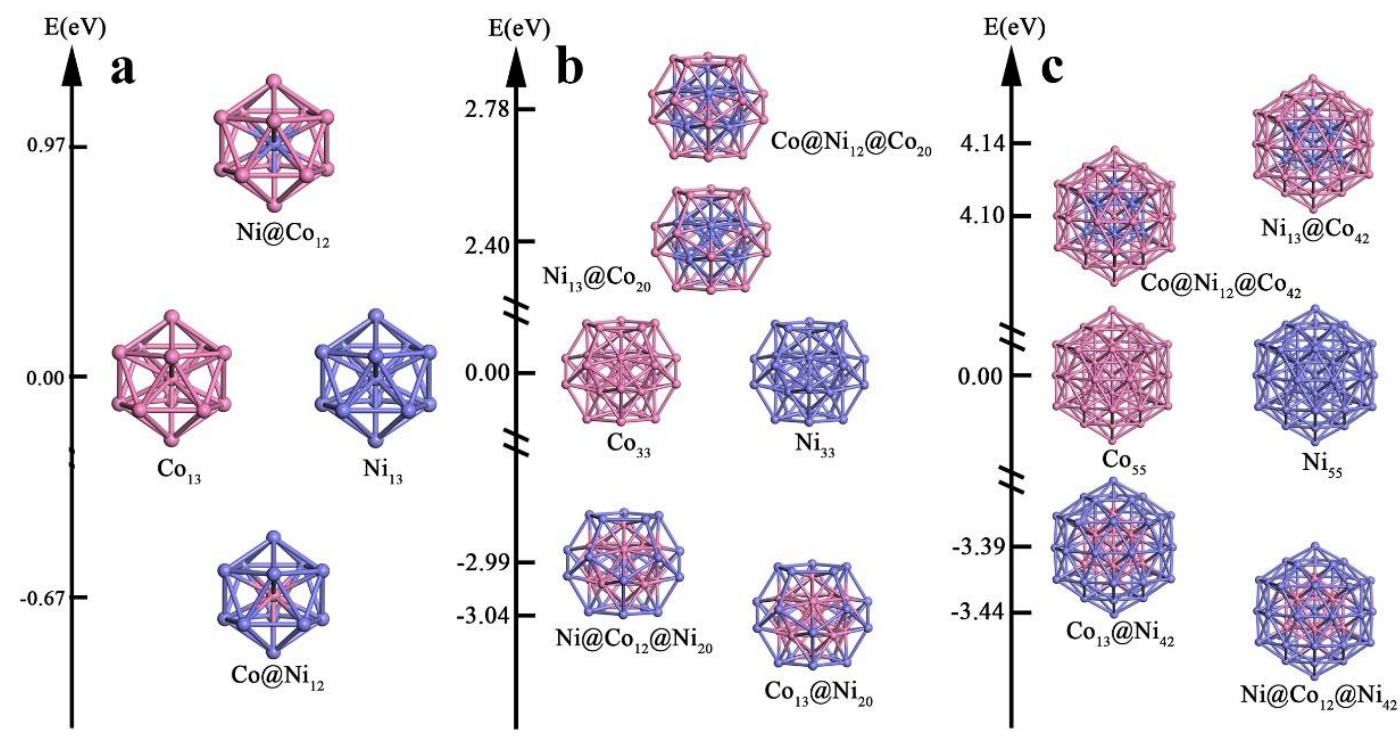

Figure 2. The excess energies of a 13-atoms b 33-atoms and c 55-atoms $\mathrm{Co}, \mathrm{Ni}$ nanoclusters. Magenta and violet spheres represent $\mathrm{Co}$ and $\mathrm{Ni}$ atoms, respectively.

With the excess energies displayed in Figure 2, we can easily know that the relative 
stabilities of these Co-Ni nanoclusters follow the order $\mathrm{Ni} @ \mathrm{Co}_{12}(0.97 \mathrm{eV})<\mathrm{Co}_{13} / \mathrm{Ni}_{13}$ $(0.00 \mathrm{eV})<\mathrm{Co} @ \mathrm{Ni}_{12}(-0.67 \mathrm{eV})\left(\right.$ Fig. 2a). Co@Ni ${ }_{12} @ \mathrm{Co}_{20}(2.78 \mathrm{eV})<\mathrm{Ni}_{13} @ \mathrm{Co}_{20}$ $(2.40 \mathrm{eV})<\mathrm{Co}_{55} / \mathrm{Ni}_{55}(0.00 \mathrm{eV})<\mathrm{Ni} @ \mathrm{Co}_{13} @ \mathrm{Ni}_{20}(-2.99 \mathrm{eV})<\mathrm{Co}_{13} @ \mathrm{Ni}_{20}(-3.04 \mathrm{eV})$ (Fig. 2b). Ni13 @Co42 $\left(4.14\right.$ eV) < Co@Ni $@ \mathrm{Ni}_{12} @ \mathrm{Co}_{42}(4.10 \mathrm{eV})<\mathrm{Co}_{55} / \mathrm{Ni}_{55}(0.00 \mathrm{eV})<$ $\mathrm{Co}_{13} @ \mathrm{Ni}_{42}(-3.39 \mathrm{eV})<\mathrm{Ni} @ \mathrm{Co}_{12} @ \mathrm{Ni}_{42}(-3.44 \mathrm{eV})($ Fig. 2c). Research shows that the $\mathrm{Co} @ \mathrm{Ni}_{12}(-0.67 \mathrm{eV})$ cluster, which with a $\mathrm{Ni}$ surface-shell, possessing the lowest excess energies below than the corresponding monometallic $\mathrm{Co}_{13} / \mathrm{Ni}_{13}(0.00 \mathrm{eV})$, however the Ni@Co12 $(0.97$ eV) cluster, which with a Co surface-shell, have the highest excess energies than the corresponding monometallic $\mathrm{Co}_{13} / \mathrm{Ni}_{13}(0.00 \mathrm{eV})$. Analogously, the 33-atoms nanoclusters system in Figure 2b displays the $\mathrm{Ni} @ \mathrm{Co}_{13} @ \mathrm{Ni}_{20}(-2.99 \mathrm{eV})$ and $\mathrm{Co}_{13} @ \mathrm{Ni}_{20}(-3.04 \mathrm{eV})$ nanoclusters, which with a Ni surface-shell, below than the corresponding monometallic $\mathrm{Co}_{33} / \mathrm{Ni}_{33}(0.00 \mathrm{eV})$ and $\mathrm{Co} @ \mathrm{Ni}_{12} @ \mathrm{Co}_{20}(2.78 \mathrm{eV})$, $\mathrm{Ni}_{13} @ \mathrm{Co}_{20}(2.40 \mathrm{eV})$ clusters, which with a Co surface-shell, are above it. However, it is interesting that two-layer $\mathrm{Co}_{13} @ \mathrm{Ni}_{20}$ has lower excess energy than three-layer $\mathrm{Ni} @ \mathrm{Co}_{13} @ \mathrm{Ni}_{20}$ by only 0.05 eV, while three-layer $\mathrm{Co} @ \mathrm{Ni}_{12} @ \mathrm{Co}_{20}$ has higher excess energy than two-layer $\mathrm{Ni}_{13} @ \mathrm{Co}_{20}$ by $0.38 \mathrm{eV}$. More interestingly, it is roughly the same in the 55-atoms nanoclusters system in Figure 2c, but somewhat different because threelayer $\mathrm{Ni} @ \mathrm{Co}_{12} @ \mathrm{Ni}_{42}$ has lower excess energy than two-layer $\mathrm{Co}_{13} @ \mathrm{Ni}_{42}$ by only 0.05 eV, while two-layer $\mathrm{Ni}_{13} @ \mathrm{Co}_{20}$ has higher excess energy than three-layer Co@ $\mathrm{Ni}_{12} @ \mathrm{Co} 42$ by only $0.04 \mathrm{eV}$. As a result, it is contrary to the stability tendency in the 33-atoms nanoclusters system (two-layer $>$ three-layer) and 55-atoms nanoclusters system (three-layer $>$ two-layer). The total energy, excess energy, magnetic moment have displayed in Table I. 
Table 1 Calculated results of total, excess, and segregation energies and magnetic moment of monometallic and bimetallic Co-Ni core-shell nanoclusters.

\begin{tabular}{|c|c|c|c|}
\hline Nanoparticle & $\mathrm{E}_{\text {total }}(\mathrm{eV})$ & $\begin{array}{l}E_{\text {exc }} \\
(\mathrm{eV}) \\
\end{array}$ & $\begin{array}{c}\text { Magnetic } \\
\text { moment }(\mu \mathrm{B})\end{array}$ \\
\hline $\mathrm{Co}_{13}$ & -67.09536517 & 0.00 & 21.77 \\
\hline $\mathrm{Ni}_{13}$ & -49.92385286 & 0.00 & 8.00 \\
\hline $\mathrm{Ni@ \textrm {Co } _ { 1 2 }}$ & -64.80702514 & 0.97 & 20.64 \\
\hline $\mathrm{Co} @ \mathrm{Ni}_{12}$ & -51.91461042 & -0.67 & 9.05 \\
\hline $\mathrm{Co}_{33}$ & -190.2894001 & 0.00 & 60.89 \\
\hline $\mathrm{Ni}_{33}$ & -140.1012015 & 0.00 & 28.34 \\
\hline $\mathrm{Ni}_{13} @ \mathrm{Co}_{20}$ & -168.1124673 & 2.40 & 51.77 \\
\hline $\mathrm{Co}_{13} @ \mathrm{Ni}_{20}$ & -162.9074197 & -3.04 & 40.69 \\
\hline 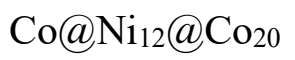 & -169.2618989 & 2.78 & 51.23 \\
\hline $\mathrm{Ni@Co}{ }_{12} @ \mathrm{Ni}_{20}$ & -161.3447238 & -2.99 & 39.69 \\
\hline $\mathrm{Co} 55$ & -331.8413366 & 0.00 & 104.45 \\
\hline $\mathrm{Ni}_{55}$ & -249.8686900 & 0.00 & 38.89 \\
\hline $\mathrm{Ni}_{13} @ \mathrm{Co}_{42}$ & -308.3245820 & 4.14 & 88.51 \\
\hline $\mathrm{Co}_{13} @ \mathrm{Ni}_{42}$ & -272.6302020 & -3.39 & 52.43 \\
\hline $\mathrm{Co@Ni12@Co42}$ & -309.8582922 & 4.10 & 91.26 \\
\hline $\mathrm{Ni@Co}{ }_{12} @ \mathrm{Ni}_{42}$ & -271.1891057 & -3.44 & 51.62 \\
\hline
\end{tabular}

The bimetallic Co-Ni core-shell nanoclusters have a more complex charge distribution

Under the situation of bimetallic core-shell, the nanoclusters with the hetero-nuclear metal atoms may further be enhanced or inhibited the charge transfer among the inner and surface atoms due to the different electronic structures and electronegativity. In order to father study the charge density, which is affected by the switch of the innercore and surface-shell atoms, of the bimetallic Co-Ni core-shell nanoclusters, Bader charge analysis, and the results are displayed in Figure 3. In this figure, the negative Bader charge corresponds to net charge accumulation, while the positive Bader charge indicates net charge depletion on the core-shell atoms. Detailed Bader charge data can be found in the supporting information Table S3. 


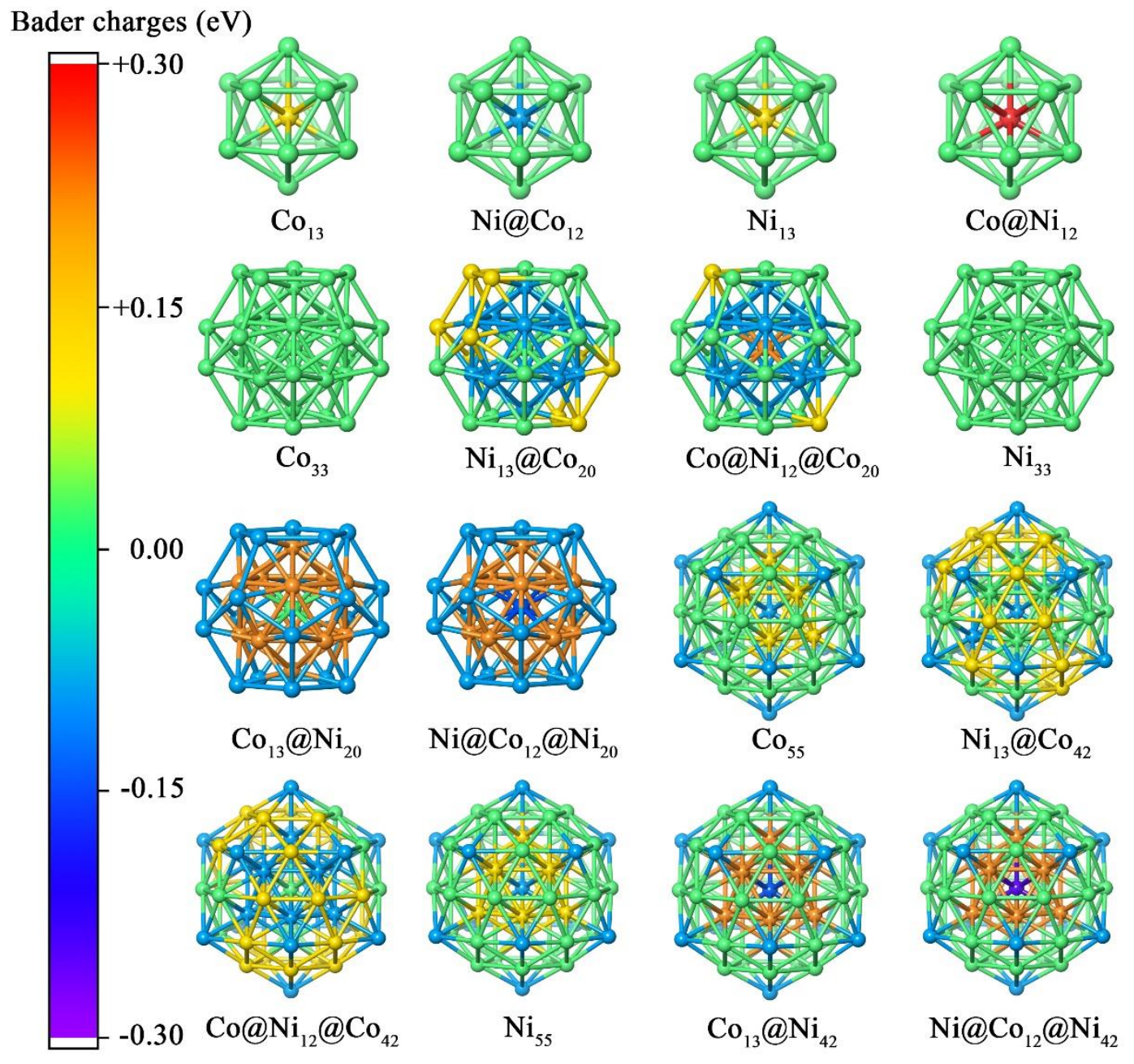

Figure 3. The Bader charges analysis of the 13, 33, and 55-atoms monometallic and bimetallic Co-Ni core-shell nanoclusters.

As known to all, the electron tends to transfer from inner atoms to surface atoms due to the surface effect in monometallic nanoclusters generally. For 13-atoms monometallic nanoclusters, the net charge transfer from one core atom to 12 surface-shell atoms is 0.10 electron $(e)$ for $\mathrm{Co}_{13}$ and $0.09 e$ for $\mathrm{Ni}_{13}$. For 33-atoms monometallic nanoclusters, the net charge transfer from 13 inner atoms to 20 surface-shell atoms is 0.49 electron (e) for $\mathrm{Co}_{33}$ and $0.50 e$ for $\mathrm{Ni}_{33}$. The charge distributions of $\mathrm{Co}_{33}$ and $\mathrm{Ni}_{33}$ are +0.02 +0.47 and $-0.49 e$ and $+0.03+0.47$ and $-0.50 e$ for the core, middle-shell, and surfaceshell atoms, respectively. Interestingly, the charge distributions of Co55 are $-0.13,+0.70$, and $-0.57 e$ for the core, middle-shell, and surface-shell atoms, respectively. Similarly, the charge distributions of $\mathrm{Ni}_{55}$ are $-0.14,+0.82$, and -0.68 e for the core, middle-shell, 
and surface-shell atoms, respectively.

The electron transfer from $\mathrm{Co}$ to $\mathrm{Ni}$ in the heterojunction of the bimetallic Co-Ni coreshell nanoclusters would be further enhanced due to the difference of electronegativity between Co (1.88) and Ni (1.91). As the Bader charge analysis displayed in Figure 3, the charge always transfers from Co atoms to $\mathrm{Ni}$ atoms. Besides, charge transfer would also be enhanced from $\mathrm{Co}$ to $\mathrm{Ni}$ due to the synergistic effects of the surface when $\mathrm{Ni}$ locates at the surface and Co locates at the inner-shell. For the 13-atoms bimetallic nanoclusters $\mathrm{Co} @ \mathrm{Ni}_{12}$, the net charge of $0.26 e$ is transferred from one Co core atom to 12 surface-shell $\mathrm{Ni}$ atoms, leading to a more negative surface-shell than that of $\mathrm{Ni}_{13}$ by 0.17 e. Surprisingly, the charge transfer has been dramatically enhanced in the bimetallic nanoclusters $\mathrm{Co}_{13} @ \mathrm{Ni}_{20}$ and $\mathrm{Co}_{13} @ \mathrm{Ni}_{42}$, resulting in a much more negative surfaceshell than that of $\mathrm{Ni}_{33}$ and $\mathrm{Ni}_{55}$ by $1.51 e$ and $1.15 e$ respectively. The net charges of $2.01 e$ and 1.83e are transferred from $13 \mathrm{Co}$ inner atoms to $\mathrm{Ni}$ surface in $\mathrm{Co}_{13} @ \mathrm{Ni}_{20}$ and Co13@Ni42. An interesting phenomenon appears in $\mathrm{Co}_{13} @ \mathrm{Ni}_{42}$ that the net charges of $0.20 e$ are transferred from the Co middle-shell atoms to the core atom Co. Three-shell

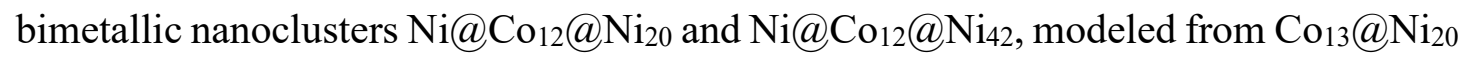
and $\mathrm{Co}_{13} @ \mathrm{Ni}_{42}$ by switching the one Co core-atom with $\mathrm{Ni}$ atom, the net charge of 0.16 and $2.03 e$ is transferred from 12 Co middle-shell atoms to one core and $20 \mathrm{Ni}$ surface atoms, respectively in $\mathrm{Co}_{13} @ \mathrm{Ni}_{20}$, and similarly, the net charge of 0.32 and $1.87 e$ is transferred from $12 \mathrm{Co}$ middle-shell atoms to one core and $42 \mathrm{Ni}$ surface atoms, respectivelyin $\mathrm{Co}_{13} @ \mathrm{Ni}_{42}$.

The charge transfer from Co to Ni would be inhibited due to the mutually offset of the surface and electronegativity effects. For 13-atoms Ni@Co12, the net charge of $0.09 e$ is transferred from 12 Co surface atoms to the Ni core atom, leading to a more positive surface-shell than that of $\mathrm{Co}_{13}$ by $0.19 e$. For the bimetallic nanoclusters $\mathrm{Ni}_{13} @ \mathrm{Co}_{20}$ and $\mathrm{Ni}_{13} @ \mathrm{Co}_{42}$, the net charges of $0.99 e$ and 0.66e are transferred from Co surface-shell atoms to $13 \mathrm{Ni}$ inner atoms, respectively. For the bimetallic nanoclusters $\mathrm{Co} @ \mathrm{Ni}_{12} @ \mathrm{Co}_{20}$, the net charges of 0.16 and 0.92e are transferred from the one core 
and 20 surface Co atoms to $12 \mathrm{Ni}$ middle-shell atoms, respectively, and similar with the $\mathrm{Co} @ \mathrm{Ni}_{12} @ \mathrm{Co}_{42}$, the net charges of 0.03 and 0.67e are transferred from the one core and 20 surface Co atoms to $12 \mathrm{Ni}$ middle-shell atoms, respectively.

\section{Ni-surface clusters have higher chemical activity than Co-surface}

With the different charge transfer, the different chemical activities of bimetallic $\mathrm{Co}-\mathrm{Ni}$ core-shell nanoclusters may be endowed, which still needs a further understanding of the charge-transfer-induced chemical activity. The density of states (DOS) onto the dband of these monometallic and bimetallic $\mathrm{Co}-\mathrm{Ni}$ core-shell nanoclusters was calculated and displayed in Figure 4. The Ni@Co bimetallic nanoclusters with the Co surface shell, the d-band states shift away from the Fermi level compared to that of the Co monometallic nanoclusters. Figures 4(a)-5(h) show that the d-band centers shift from $-1.46\left(\mathrm{Co}_{13}\right)$ to $-1.62 \mathrm{eV}\left(\mathrm{Ni} @ \mathrm{Co}_{12}\right)$ for 13-atomS nanoclusters, from - $1.72\left(\mathrm{Co}_{33}\right)$ to-1.76eV $\left(\mathrm{Ni}_{13} @ \mathrm{Co}_{20}\right)$ and to-1.76 eV $\left(\mathrm{Co} @ \mathrm{Ni}_{12} @ \mathrm{Co}_{20}\right)$ for 33-atoms nanoclusters, and from-1.71 (Co55) to -1.74 eV ( $\left.\mathrm{Ni}_{13} @ \mathrm{Co} 42\right)$ and to -1.75 eV (Co@ $\left.\mathrm{Ni}_{12} @ \mathrm{Co} 42\right)$ for 55-atoms nanoclusters. Similarly, the shift of the Co@Ni bimetallic nanoclusters with the Ni surface shell, as shown in Figures 4(i)-5(p). Quantitatively, the d-band centers are -1.16 $\left(\mathrm{Ni}_{13}\right),-1.29\left(\mathrm{Co} @ \mathrm{Ni}_{12}\right) \mathrm{eV}$ for 13-atom particles, -1.47 $\left(\mathrm{Ni}_{33}\right),-1.53$ (Co13@Ni20),-1.59 (Ni@Co12@Ni20)eV for 33-atom systems and-1.41 (Ni55),-1.42 (Co13@Ni42),-1.43(Ni@Co12@Ni42) eV for 55-atoms nanoclusters. Generally, a

shallower d-band center of transition metals corresponds to higher chemical activity. ${ }^{17}$ These results show that the d-band centers of the Ni-surface nanoclusters are closer to the Fermi energy than Co-surface, indicating that the monometallic and bimetallic CoNi core-shell nanoclusters with Ni-surface have higher chemical activity than Cosurface. 


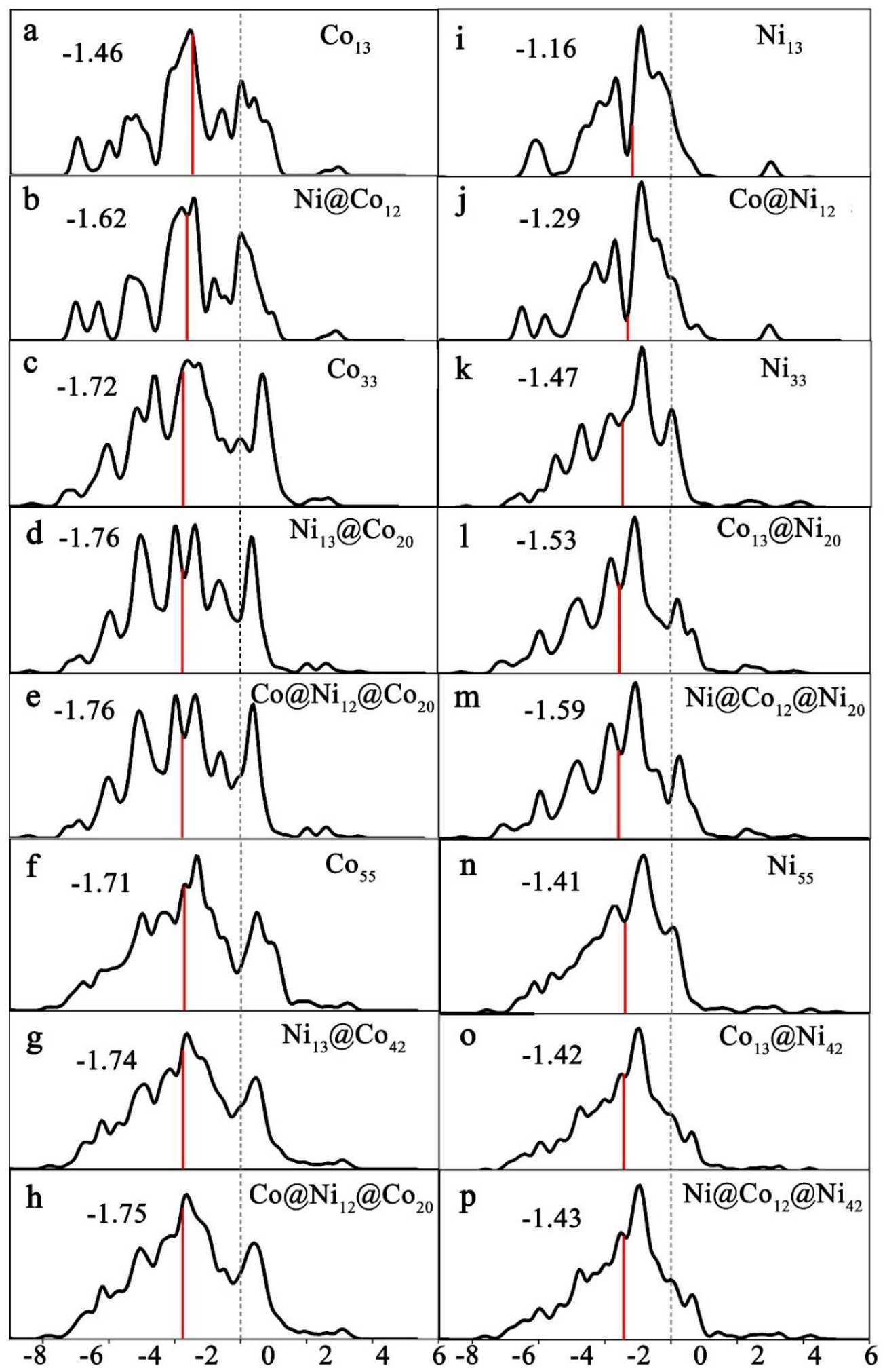

Figure 4. The densities of states projected onto the d-band of the monometallic and bimetallic Co-Ni core-shell nanoclusters. The red lines indicate the corresponding dband center $(\mathrm{eV})$. The Fermi level is set to zero energy and indicated by the vertical dashed lines. 
To further understand these nanoclusters' electronic and magnetic properties, a partial density of states (PDOS) projected onto the core, inner-shell, and surface-shell atoms are displayed in Figures 5, 6, and 7 for the 13-, 33-and 55-atoms nanoclusters, respectively. The total magnetic moments of these nanoclusters are listed in the fourth column of Table 1. The results show that all 13-atoms nanoclusters of the $\mathrm{Co}_{13}, \mathrm{Ni}_{13}$, $\mathrm{Ni@Co} 12$, and $\mathrm{Co} @ \mathrm{Ni}_{12}$ are metallic and ferromagnetic with asymmetry PDOS curves for the core and surface atoms. The monometallic and bimetallic nanoclusters with the

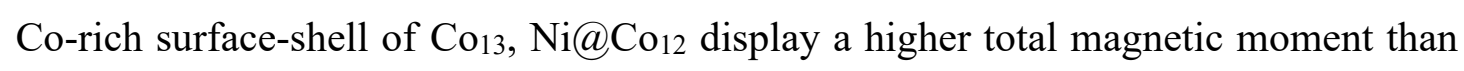
$\mathrm{Ni}_{13}, \mathrm{Co} @ \mathrm{Ni}_{12}$ with the Ni-rich surface-shell. In detail, the total magnetic moments of these nanoclusters follow the order $\mathrm{Co}_{13}\left(21.77 \mu_{B}\right)>\mathrm{Ni} @ \mathrm{Co}_{12}\left(20.64 \mu_{B}\right)>\mathrm{Co} @ \mathrm{Ni}_{12}$ $\left(9.05 \mu_{B}\right)>\mathrm{Ni}_{13}\left(8.00 \mu_{B}\right)$.

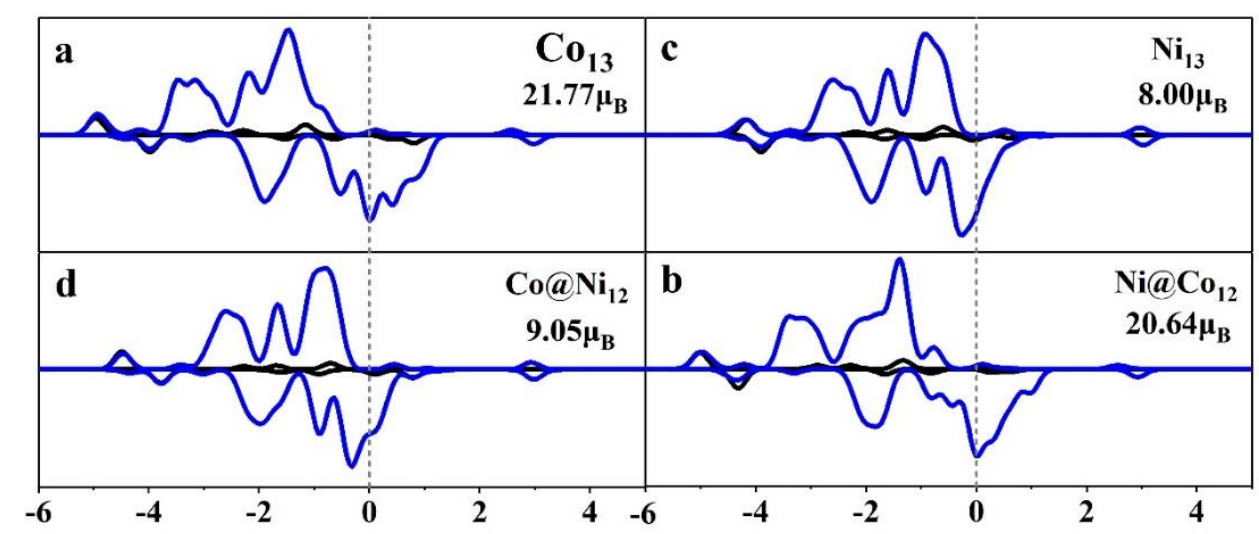

Figure 5. Partial densities of states (PDOS) are projected onto the core atom (black lines) and surface atom (blue lines) for the 13-atoms nanoclusters. The Fermi level is set to zero energy and indicated by the vertical dashed lines.

With the partial density of states (PDOS) analysis on dodecahedral 33-atoms monometallic and bimetallic nanoclusters, we found that all the atoms are metallic and ferromagnetic with asymmetry PDOS curves amount the majority and minority spins projected onto the core, middle- and surface-shell atoms (Figure 6). The $\mathrm{Co}_{33}$ has the largest total magnetic moment of $60.89 \mu_{B}$, while the total magnetic moments of twoshell $\mathrm{Ni}_{13} @ \mathrm{Co}_{20}$ and three-shell Co@ $\mathrm{Ni}_{12} @ \mathrm{Co}_{20}$ are 51.77 and $51.23 \mu_{B}$, lower than 
that of $\mathrm{Co}_{33}$ by 9.12 and $9.66 \mu_{B}$, respectively. The total magnetic moment of two-shell $\mathrm{Ni}_{13} @ \mathrm{Co}_{20}$ and three-shell $\mathrm{Co} @ \mathrm{Ni}_{12} @ \mathrm{Co}_{20}$ are weakened significantly in sequence because the core and inner shell $\mathrm{Co}$ atoms in $\mathrm{Co}_{33}$ are substituted successively by the $\mathrm{Ni}$ atoms. Interestingly, two-shell $\mathrm{Co}_{12} @ \mathrm{Ni}_{20}$ has the highest total magnetic moment of $40.69 \mu_{B}$ in the nanoparticles with a Ni surface, higher than that of the $\mathrm{Ni}_{33}$ by $12.35 \mu_{B}$ due to the Co-substitution of the middle-shell $12 \mathrm{Ni}$ atoms in $\mathrm{Ni}_{33}$. While the $\mathrm{Ni}_{33}$ has the lowest total magnetic moment of $28.34 \mu_{B}$, and the three-shell $\mathrm{Ni} @ \mathrm{Co}_{12} @ \mathrm{Ni}_{20}$ is $39.69 \mu_{B}$, lower than that of the $\mathrm{Ni}_{33}$ by $11.35 \mu_{B}$. The total magnetic moment of $33-$ atoms monometallic and bimetallic nanoclusters follows the sequence: $\mathrm{Co}_{33}\left(60.89 \mu_{B}\right)>$ $\mathrm{Co}_{13} @ \mathrm{Ni}_{20}\left(51.77 \mu_{B}\right)>\mathrm{Co} @ \mathrm{Ni}_{12} @ \mathrm{Co}_{20}\left(51.23 \mu_{B}\right)$ and $\mathrm{Co}_{13} @ \mathrm{Ni}_{20}\left(40.69 \mu_{B}\right)>$ $\mathrm{Ni} @ \mathrm{Co}_{12} @ \mathrm{Ni}_{20}\left(39.69 \mu_{B}\right)>\mathrm{Ni}_{33}\left(28.34 \mu_{B}\right)$. 


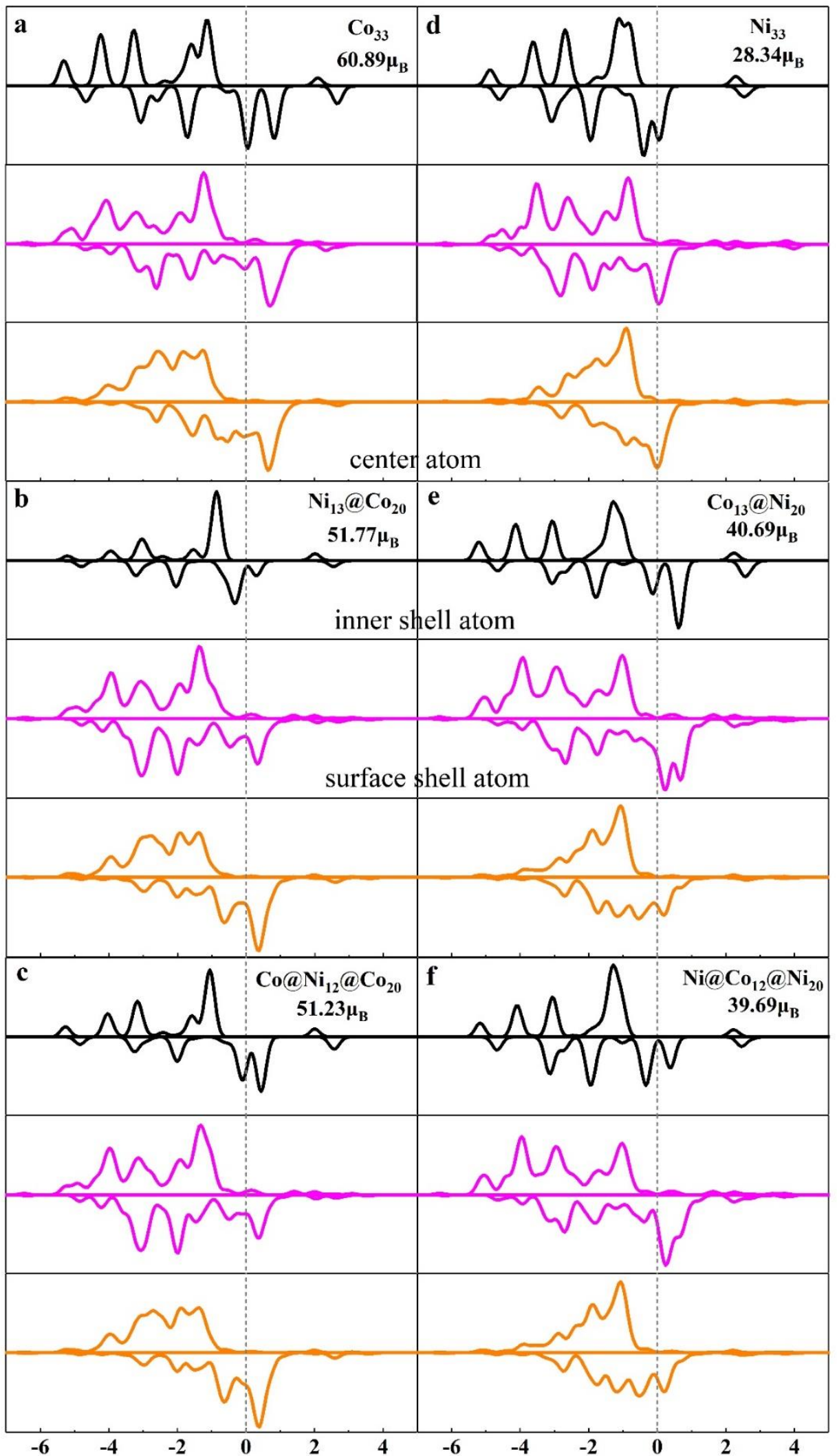

Figure 6. Partial densities of states (PDOSs) projected onto the core (black lines), innershell (magenta lines), surface atom (orange lines) for the 33-atoms nanoclusters. The Fermi level is set to zero energy and indicated by the vertical dashed lines. 
As displayed in Figure 7. for the icosahedral 55-atoms monometallic and bimetallic nanoclusters, the $\mathrm{Co}_{55}$ has the largest total magnetic moment of $104.45 \mu_{B}$, while total magnetic moments of two-shell $\mathrm{Ni}_{13} @ \mathrm{Co}_{42}$ and three-shell Co@ $\mathrm{Ni}_{12} @ \mathrm{Co}_{42}$ are 88.51 and $91.26 \mu_{B}$, lower than that of Co5s by 15.94 and $13.19 \mu_{B}$, respectively.

The total magnetic moment of three-shell Co@ $\mathrm{Ni}_{12} @ \mathrm{Co}_{42}$ and tow-shell $\mathrm{Ni}_{13} @ \mathrm{Co} 42$ is weakened in sequence because the core and inner shell Co atoms in the Co55 are substituted successively by the $\mathrm{Ni}$ atoms. In contrast, the Ni55 has the lowest total magnetic moment of $38.89 \mu_{B}$, while the total magnetic moment of tow-shell $\mathrm{Co}_{13} @ \mathrm{Ni}_{42}$ and $\mathrm{Ni} @ \mathrm{Co}_{12} @ \mathrm{Ni}_{42}$ are 52.43 and $51.62 \mu_{B}$, higher than that of $\mathrm{Ni}_{55}$ by 13.54 and 12.73 $\mu_{B}$, respectively. The total magnetic moment of two-shell $\mathrm{Co}_{13} @ \mathrm{Ni}_{42}$ and

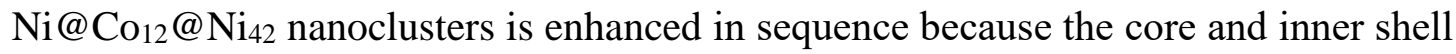
$\mathrm{Ni}$ atoms in the $\mathrm{Ni}_{55}$ are substituted successively by the Co atoms. In one word, the total magnetic moment follows the order: $\mathrm{Co} 55\left(104.45 \mu_{B}\right)>\mathrm{Co} @ \mathrm{Ni}_{12} @ \mathrm{Co}_{42}\left(91.26 \mu_{B}\right)>$ $\mathrm{Ni}_{13} @ \mathrm{Co}_{42}\left(88.51 \mu_{B}\right)$ and $\mathrm{Co}_{13} @ \mathrm{Ni}_{42}\left(52.43 \mu_{B}\right)>\mathrm{Ni} @ \mathrm{Co}_{12} @ \mathrm{Ni}_{42}\left(51.62 \mu_{B}\right)>\mathrm{Ni}_{55}$ $\left(38.89 \mu_{B}\right)$. 


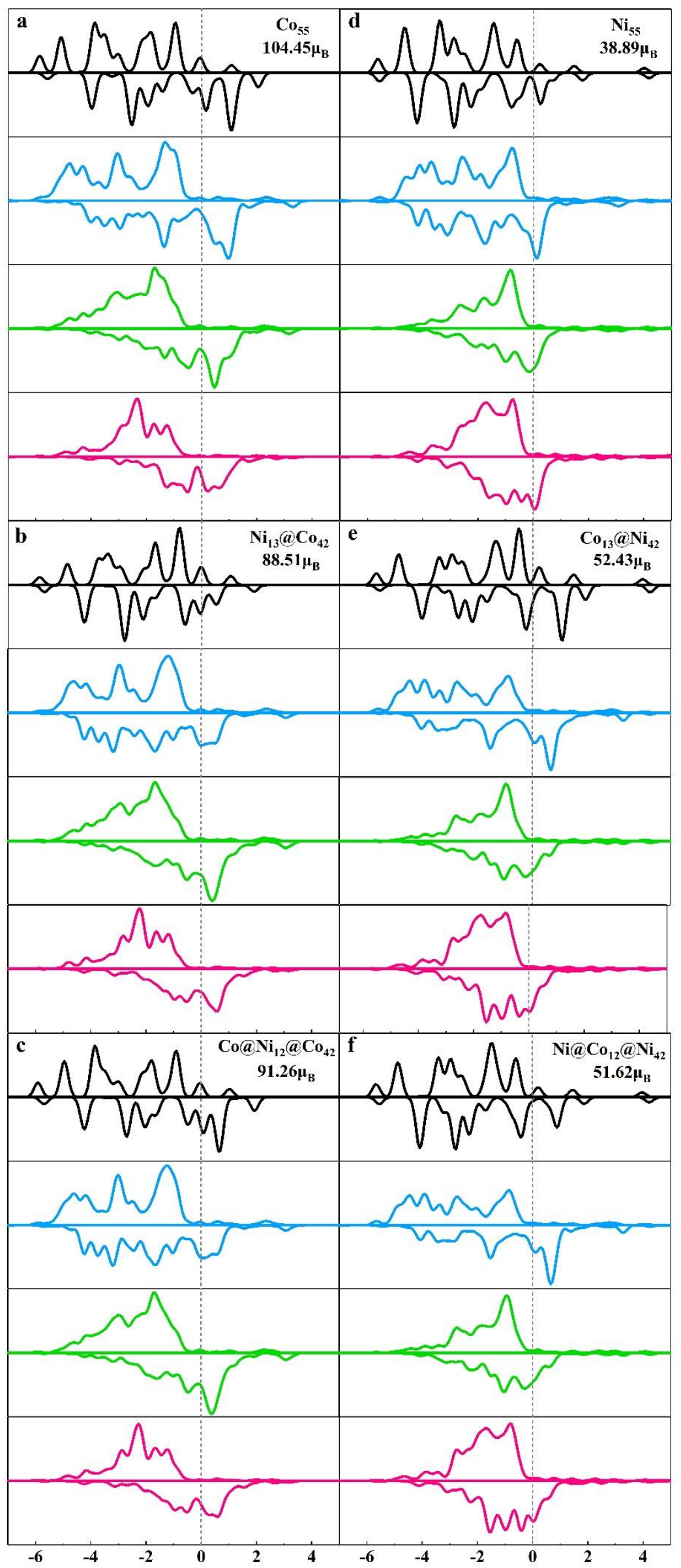


Figure 7. Partial densities of states (PDOSs) projected onto the core (black lines), innershell (blue lines), surface edge atom (green lines), and surface vertex (red lines) atom for the 55-atom nanoclusters. The Fermi level is set to zero energy and indicated by the vertical dashed lines.

By adjusting the size and electronic structures, Co@Ni $i_{12}$ shows the best HER performance

The electrocatalytic activity of Co-Ni nanoclusters in Hydrogen Evolution Reaction (HER) has been intensely scrutinized for over 20 years $^{18}$. Recently, the experimental findings indicated that the $\mathrm{Co}-\mathrm{Ni}$ nanoclusters exhibited excellent electrocatalytic activity toward the HER. ${ }^{6,19,20}$ In order to better understand the catalytic activity difference of the Co-Ni monometallic and bimetallic nanoclusters in HER, we have further calculated the adsorption of hydrogen.

The generally accepted mechanism of the Hydrogen Evolution Reaction (HER) is that an initial state $\left(\mathrm{H}^{+}+e^{-}\right)$, an intermediate state (adsorbed $\left.\mathrm{H}, \mathrm{H}^{*}\right)$, and a product state $\left(1 / 2 \mathrm{H}_{2}\right)$ existed in an HER pathway. In addition, the reactor rate of the overall HER is directly determined by the hydrogen adsorption free energy $\left(\Delta \mathrm{G}_{\mathrm{H}^{*}}\right){ }^{21,22}$ Thus, $\Delta \mathrm{G}_{\mathrm{H}^{*}}$ has been successfully employed as a good indicator for correlating theoretical predictions with experimental measurements of HER catalytic activities. ${ }^{23}$ The optimum value of $\Delta \mathrm{G}_{\mathrm{H}^{*}}$ should be zero, implying that hydrogen adsorbent to the surface neither too weakly nor too strongly ${ }^{24}$. The absolute value of free energy of hydrogen adsorption $\left|\Delta G_{\mathrm{H}^{*}}\right|<0.1 \mathrm{eV}$ can be defined as the optimal active sites $^{7}$, demonstrated superior HER performance. The $\Delta G_{\mathrm{H}^{*}}$ is expressed as follows ${ }^{25}$ :

$$
\Delta G_{H^{*}}=\Delta E_{H^{*}}+\Delta E_{Z P E}-T \Delta S_{H^{*}}
$$

where $\Delta G_{H^{*}}, \Delta E_{Z P E}$, and $T \Delta S_{H^{*}}$ are the chemisorption energy of atomic hydrogen on the given surface, zero-point energy difference between the adsorbed and the gas phase, and the entropy change of $\mathrm{H}^{*}$ adsorption. The zero-point energy correction can be estimated by the equation: 


$$
\Delta E_{Z P E}=E_{Z P E}\left(H^{*}\right)-\frac{1}{2} E_{Z P E}\left(H_{2}\right)
$$

where $E_{Z P E}\left(H^{*}\right)$ and $E_{Z P E}\left(H_{2}\right)$ are calculated by vibration frequency calculation.In fact, the vibrational entropy in the adsorbed state is small, which means that the entropy of adsorption of $\frac{1}{2} H_{2}$ is $\Delta S_{H^{*}} \cong-\frac{1}{2} S_{H_{2}}^{0}$, where $S_{H_{2}}^{0}$ is the entropy of $H_{2}$ in the gas phase at standard conditions. Therefore, the value of $T \Delta S_{H^{*}}=-\frac{1}{2} T S_{H_{2}}^{0}=-0.20$ $\mathrm{eV}^{26,27}$. The value of $\Delta E_{H^{*}}$ is calculated as:

$$
\Delta E_{H^{*}}=E_{\text {tot }}-E_{\text {sub }}-\frac{1}{2} E_{H_{2}}
$$

where $E_{\text {tot }}$ and $E_{\text {sub }}$ are the energies of $\mathrm{H}$ absorbed systems and the clean given clusters, respectively, and $E_{\mathrm{H}_{2}}$ is the energy of molecular $\mathrm{H}_{2}$ in the gas phase.
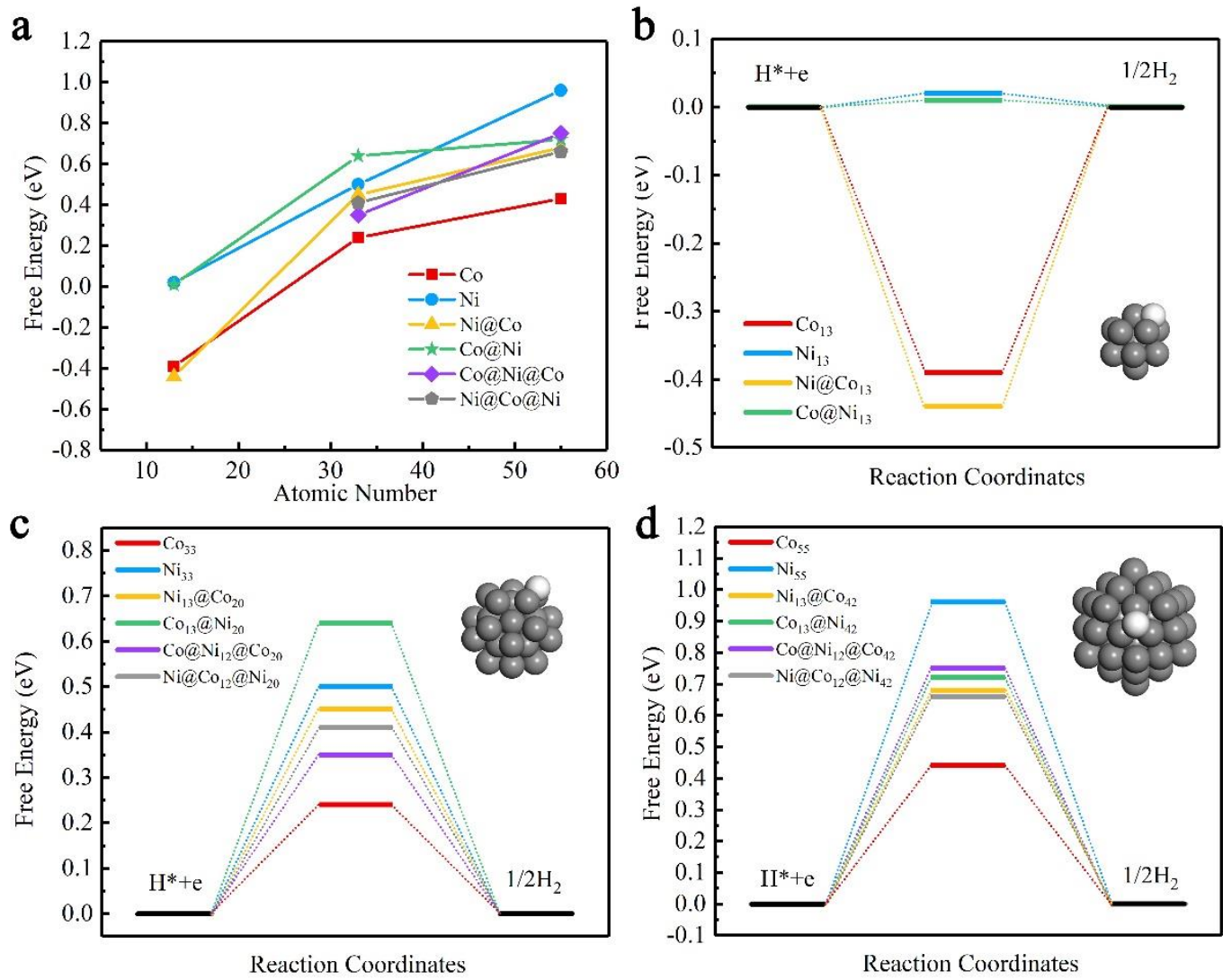

Figure 8. Calculated Gibbs free-energy diagram for HER on monometallic and bimetallic Co-Ni core-shell nanoclusters. 
Figure 8 shows the calculated free energy diagram for hydrogen adsorption on 13-, 33-, and 55-atoms monometallic and bimetallic Co-Ni core-shell nanoclusters. In 13-atoms nanoclusters (Figure 8b), the absolute value of free energy of hydrogen adsorption $\left|\Delta \mathrm{G}_{\mathrm{H}^{*}}\right|$ follows the order: $\mathrm{Co} @ \mathrm{Ni}_{12}(0.01 \mathrm{eV})<\mathrm{Ni}_{13}(0.02 \mathrm{eV})<\mathrm{Co}_{13}(-0.39 \mathrm{eV})<$ $\mathrm{Ni} @ \mathrm{Co}_{12}(-0.44 \mathrm{eV})$. This also represents the performance order of HER is $\mathrm{Co} @ \mathrm{Ni}_{12}$ $(0.01 \mathrm{eV})>\mathrm{Ni}_{13}(0.02 \mathrm{eV})>\mathrm{Co}_{13}(0.39 \mathrm{eV})>\mathrm{Ni} @ \mathrm{Co}_{12}(0.44 \mathrm{eV})$. In Figure 8c, we can intuitively know that the HER performance of the 33-atoms nanoclusters from high to low is $\mathrm{Co}_{33}(0.24 \mathrm{eV})>\mathrm{Co} @ \mathrm{Ni}_{12} @ \mathrm{Co}_{20}(0.35 \mathrm{eV})>\mathrm{Ni} @ \mathrm{Co}_{12} @ \mathrm{Ni}_{20}(0.41 \mathrm{eV})>$ $\mathrm{Ni}_{13} @ \mathrm{Co}_{42}(0.45 \mathrm{eV})>\mathrm{Ni}_{33}(0.50 \mathrm{eV})>\mathrm{Co}_{13} @ \mathrm{Ni}_{20}(0.64 \mathrm{eV})$. Similarly, HER performance of the 55-atoms nanoclusters from high to low is $\mathrm{Co}_{55}(0.44 \mathrm{eV})>$ $\mathrm{Ni} @ \mathrm{Co}_{12} @ \mathrm{Ni}_{42}(0.66 \mathrm{eV})>\mathrm{Ni}_{13} @ \mathrm{Co}_{42}(0.68 \mathrm{eV})>\mathrm{Co}_{13} @ \mathrm{Ni}_{42}(0.72 \mathrm{eV})>$ $\mathrm{Co} @ \mathrm{Ni}_{12} @ \mathrm{Co}_{42}(0.75 \mathrm{eV})>\mathrm{Ni}{ }_{55}(0.96 \mathrm{eV})$. Detailed HER analysis data can be found in the supporting information Table S4.

In general, the calculation and analysis of HER performance indicate that $\mathrm{Co} @ \mathrm{Ni}_{12}$ $\left(\left|\Delta \mathrm{G}_{\mathrm{H}^{*}}\right|=0.01 \mathrm{eV}\right)$ shows the best HER performance. In addition, in Figure 8a, we can understand that the Gibbs free energy of hydrogen adsorption $\Delta \mathrm{G}_{\mathrm{H}^{*}}$ of Co-Ni nanoclusters is positively related to the size of the clusters, and the $\Delta \mathrm{G}_{\mathrm{H}^{*}}$ can be adjusted within a certain range by changing the electronic structure of the clusters.

\section{CONCLUSIONS}

In conclusion, the geometrical structure, thermodynamic stability, chemical activity, electronic and magnetic properties, and catalytic activity in HER of the 13- 33- and 55atoms monometallic and bimetallic Co-Ni core-shell nanoclusters were systematically studied using DFT calculations. Through structure analysis, We know the Co-Ni Coreshell alloyed clusters show similar geometries. We found that Ni-surface nanoclusters have higher relative stability than Co-surface nanoclusters by excess energy analysis. More interestingly, Ni-surface nanoclusters show higher chemical activity than Cosurface by DOS analysis using the d-band center theory. In addition, we found that CoNi nanoclusters have good magnetic properties and complex electronic structures. To 
further understand the catalytic properties of these nanoclusters, we further calculated the free energy of hydrogen adsorption and systematically studied the HER performance of Co-Ni nanoclusters. Finally, we found that the Gibbs free energy of hydrogen adsorption $\Delta \mathrm{G}_{\mathrm{H}^{*}}$ of Co-Ni nanoclusters is positively related to the size of the clusters, and the $\Delta \mathrm{G}_{\mathrm{H}^{*}}$ can be adjusted within a certain range by changing the electronic structure of the clusters. By optimizing the electronic structures and promote effective charge transfer, a 13-atoms size bimetallic Co-Ni core-shell nanocluster $\mathrm{Co} @ \mathrm{Ni}_{12}$ $\left(\left|\Delta \mathrm{G}_{\mathrm{H}^{*}}\right|=0.01 \mathrm{eV}\right)$ was found to have the best HER performance.

Conflict of Interest: The authors declare that there are no conflicts of interest.

\section{SUPPORTING INFORMATION}

See Supporting Information for the optimized structure parameters of the 13- and 55atom $\mathrm{Co}$, Ni monometallic, and bimetallic $\mathrm{Co}-\mathrm{Ni}$ core-shell nanoclusters.

\section{ACKNOWLEDGMENTS}

We are grateful to the High Performance Computing Center of Nanjing Tech University for providing the computational resources. Part of the work was carried out when the author (Hengyue $\mathrm{Xu}$ ) visited Tianjin Institute of Pharmaceutical Research. We also appreciate the inspiring discussions at Nanjing Tech University, especially Dr. Qiang Wang, Dr. Dengming Ming, and Dr. Pengfei Liu, who offered valuable manuscript preparation advice. Thanks to Ye Wang, a small number of pictures were made with his help.

\section{REFERENCE}

1. Xu, H.; Shang, H.; Wang, C.; Du, Y., Ultrafine Pt-based nanowires for advanced catalysis. Advanced Functional Materials 2020, 30 (28), 2000793.

2. Xu, H.; Shang, H.; Wang, C.; Du, Y., Low-Dimensional Metallic Nanomaterials for Advanced Electrocatalysis. Advanced Functional Materials 2020, 30 (50), 2006317.

3. Wang, J.; Shao, H.; Ren, S.; Hu, A.; Li, M., Fabrication of porous Ni-Co catalytic electrode with high performance in hydrogen evolution reaction. Applied Surface Science 2021, 539. 
4. Li, S.; Wang, Y.; Peng, S.; Zhang, L.; Al-Enizi, A. M.; Zhang, H.; Sun, X.; Zheng, G., Co-Ni-Based Nanotubes/Nanosheets as Efficient Water Splitting Electrocatalysts. Advanced Energy Materials 2016, 6 (3).

5. Li, Y.; Zhang, X.; Hu, A.; Li, M., Morphological variation of electrodeposited nanostructured $\mathrm{Ni}-\mathrm{Co}$ alloy electrodes and their property for hydrogen evolution reaction. International Journal of Hydrogen Energy 2018, 43 (49), 2201222020.

6. Darband, G. B.; $\quad$ Aliofkhazraei, M.; $\quad$ Rouhaghdam, A. S.; Kiani, M., Threedimensional Ni-Co alloy hierarchical nanostructure as efficient non-noble-metal electrocatalyst for hydrogen evolution reaction. Applied Surface Science 2019, 465, 846-862.

7. Mao, X.; Wang, L.; Xu, Y.; Wang, P.; Li, Y.; Zhao, J., Computational high-throughput screening of alloy nanoclusters for electrocatalytic hydrogen evolution. npj Computational Materials 2021, 7 (1).

8. Kresse, G.; Furthmüller, J., Efficiency of ab-initio total energy calculations for metals and semiconductors using a plane-wave basis set. Computational materials science 1996, 6 (1), 15-50.

9. Perdew, J. P.; Burke, K.; Ernzerhof, M., Generalized gradient approximation made simple. Physical review letters 1996, 77 (18), 3865.

10. Kresse, G.; Joubert, D., From ultrasoft pseudopotentials to the projector augmented-wave method. Physical Review B 1999, 59 (3), 1758.

11. Blöchl, P. E., Projector augmented-wave method. Physical review B 1994, 50 (24), 17953.

12. Silaghi, M.-C.; Comas-Vives, A.; Copéret, C., CO2 Activation on $\mathrm{Ni} / \gamma-$ A12O3 Catalysts by First-Principles Calculations: From Ideal Surfaces to Supported Nanoparticles. ACS Catalysis 2016, 6 (7), 4501-4505.

13. Sanville, E.; Kenny, S. D.; Smith, R.; Henkelman, G., Improved grid-based algorithm for Bader charge allocation. Journal of computational chemistry 2007, 28 (5), 899-908.

14. Henkelman, G.; Arnaldsson, A.; Jónsson, H., A fast and robust algorithm for Bader decomposition of charge density. Computational Materials Science 2006, 36 (3), 354-360.

15. Ferrando, R.; Jellinek, J.; Johnston, R. L., Nanoalloys: from theory to applications of alloy clusters and nanoparticles. Chemical reviews 2008, 108 (3), 845910.

16. Piotrowski, M. J.; Piquini, P.; Da Silva, J. L., Platinum-Based Nanoalloys Pt $\mathrm{n}$ TM55-n $(\mathrm{TM}=\mathrm{Co}, \mathrm{Rh}, \mathrm{Au})$ : A Density Functional Theory Investigation. The Journal of Physical Chemistry C 2012, 116 (34), 18432-18439.

17. Hammer, B.; Nørskov, J., Impact of Surface Science on Catalysis ed BC Gates and H Knözinger. London: Academic) p: 2000.

18. Correia, A. N.; Machado, S. A.; Avaca, L. A., Studies of the hydrogen evolution reaction on smooth $\mathrm{Co}$ and electrodeposited $\mathrm{Ni}-\mathrm{Co}$ ultramicroelectrodes. Electrochemistry communications 1999, 1 (12), 600-604.

19. González-Buch, C.; Herraiz-Cardona, I.; Ortega, E.; García-Antón, J.; 
Pérez-Herranz, V., Synthesis and characterization of macroporous $\mathrm{Ni}$, Co and $\mathrm{Ni}-\mathrm{Co}$ electrocatalytic deposits for hydrogen evolution reaction in alkaline media. International journal of hydrogen energy 2013, 38 (25), 10157-10169.

20. Lupi, C.; Dell'Era, A.; Pasquali, M., Nickel-cobalt electrodeposited alloys for hydrogen evolution in alkaline media. international journal of hydrogen energy 2009, 34 (5), 2101-2106.

21. Benck, J. D.; Hellstern, T. R.; Kibsgaard, J.; Chakthranont, P.; Jaramillo, T. F., Catalyzing the Hydrogen Evolution Reaction (HER) with Molybdenum Sulfide Nanomaterials. ACS Catal. 2014, 4 (11), 3957-3971.

22. Jiao, Y.; Zheng, Y.; Jaroniec, M. T.; Qiao, S. Z., Design of electrocatalysts for oxygen- and hydrogen-involving energy conversion reactions. Chem. Soc. Rev. 2015, 44 (8), 2060-2086.

23. Tang, Y.-J.; Wang, Y.; Wang, X.-L.; Li, S.-L.; Huang, W.; Dong, L.Z.; Liu, C.-H.; Li, Y.-F.; Lan, Y.-Q., Molybdenum Disulfide/Nitrogen-Doped Reduced Graphene Oxide Nanocomposite with Enlarged Interlayer Spacing for Electrocatalytic Hydrogen Evolution. Advanced Energy Materials 2016, 6 (12).

24. Seh, Z. W.; Kibsgaard, J.; Dickens, C. F.; Chorkendorff, I. B.; Norskov, J. K.; Jaramillo, T. F., Combining theory and experiment in electrocatalysis: Insights into materials design. Science 2017, 355 (6321), 146-+.

25. Yang, Y.; Lun, Z. Y.; Xia, G. L.; Zheng, F. C.; He, M. N.; Chen, Q. W., Non-precious alloy encapsulated in nitrogen-doped graphene layers derived from MOFs as an active and durable hydrogen evolution reaction catalyst. Energy Environ. Sci. 2015, 8 (12), 3563-3571.

26. Nørskov, J. K.; Bligaard, T.; Logadottir, A.; Kitchin, J.; Chen, J. G.; Pandelov, S.; Stimming, U., Trends in the exchange current for hydrogen evolution. Journal of The Electrochemical Society 2005, 152 (3), J23.

27. Wang, Q.; Lu, X.; Zhen, Y.; Li, W.-q.; Chen, G.-h.; Yang, Y., Structure, stability, electronic, magnetic, and catalytic properties of monometallic $\mathrm{Pd}, \mathrm{Au}$, and bimetallic $\mathrm{Pd}-\mathrm{Au}$ core-shell nanoparticles. The Journal of chemical physics 2018, 149 (24), 244307. 


\title{
Supporting information
}

\section{Hydrogen evolution reaction on Co-Ni core-shell nanoclusters in different sizes: A DFT investigation from geometric structures to electronic structures}

\author{
Hengyue $\mathrm{Xu}^{*}$
}

*State Key Laboratory of Chemical Oncogenomics, Tsinghua Shenzhen International Graduate School, Tsinghua University, Shenzhen, People's Republic of China.

\section{Corresponding author:}

Hengyue Xu, Email: xuhy21@mails.tsinghua.edu.cn

ORCID iD https://orcid.org/0000-0003-4438-9647

\section{A. Structures of Co-Ni core-shell nanoclusters}

1. 13-atoms Co-Ni core-shell nanoclusters
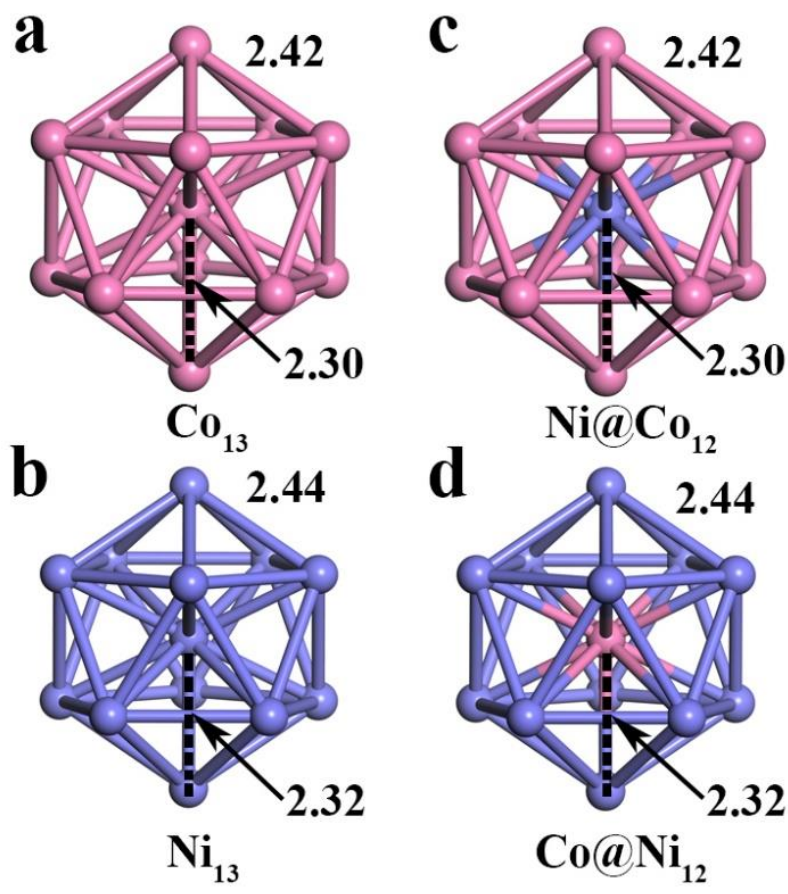

Figure S1. Optimized structures of 13-atoms monometallic and bimetallic Co-Ni coreshell nanoclusters. The bond lengths are displayed in angstroms. 
With spin-polarized DFT calculations, the 13-atoms monometallic and bimetallic Co$\mathrm{Ni}$ core-shell nanoclusters are displayed an icosahedral geometrical structure corresponding to the lowest energy. (Figure S1) There are 1 core and 12 identical surface shell atoms with coordination of 6 existing in these structures, which have the exact interatomic distances—2.30 and $2.32 \AA$ between the center atom and its adjacent 12 identical surface shell atoms in monometallic $\mathrm{Co}_{13}$ and $\mathrm{Ni}_{13}$, respectively.

The bimetallic Ni@Co12 and Co@Ni12, which derived from the monometallic $\mathrm{Co}_{13}$ and $\mathrm{Ni}_{13}$ icosahedral structures by replacing core atom, displaying the interatomic distances between the central atom and its adjacent 12 identical surface shell atoms in bimetallic are the same with the in monometallic. It is exactly the same surface adjoin interatomic distance, which is 2.42 and $2.44 \AA$ in $\mathrm{Co}$ and $\mathrm{Ni}$, respectively, between monometallic and bimetallic Co-Ni core-shell nanoclusters. Overall, the changes in the geometry of the $\mathrm{Ni} @ \mathrm{Co}_{12}$ and $\mathrm{Co} @ \mathrm{Ni}_{12}$ configurations are negligible compared to the monometallic $\mathrm{Co}_{13}$ and $\mathrm{Ni}_{13}$.

\section{33-atoms Co-Ni core-shell nanoclusters}
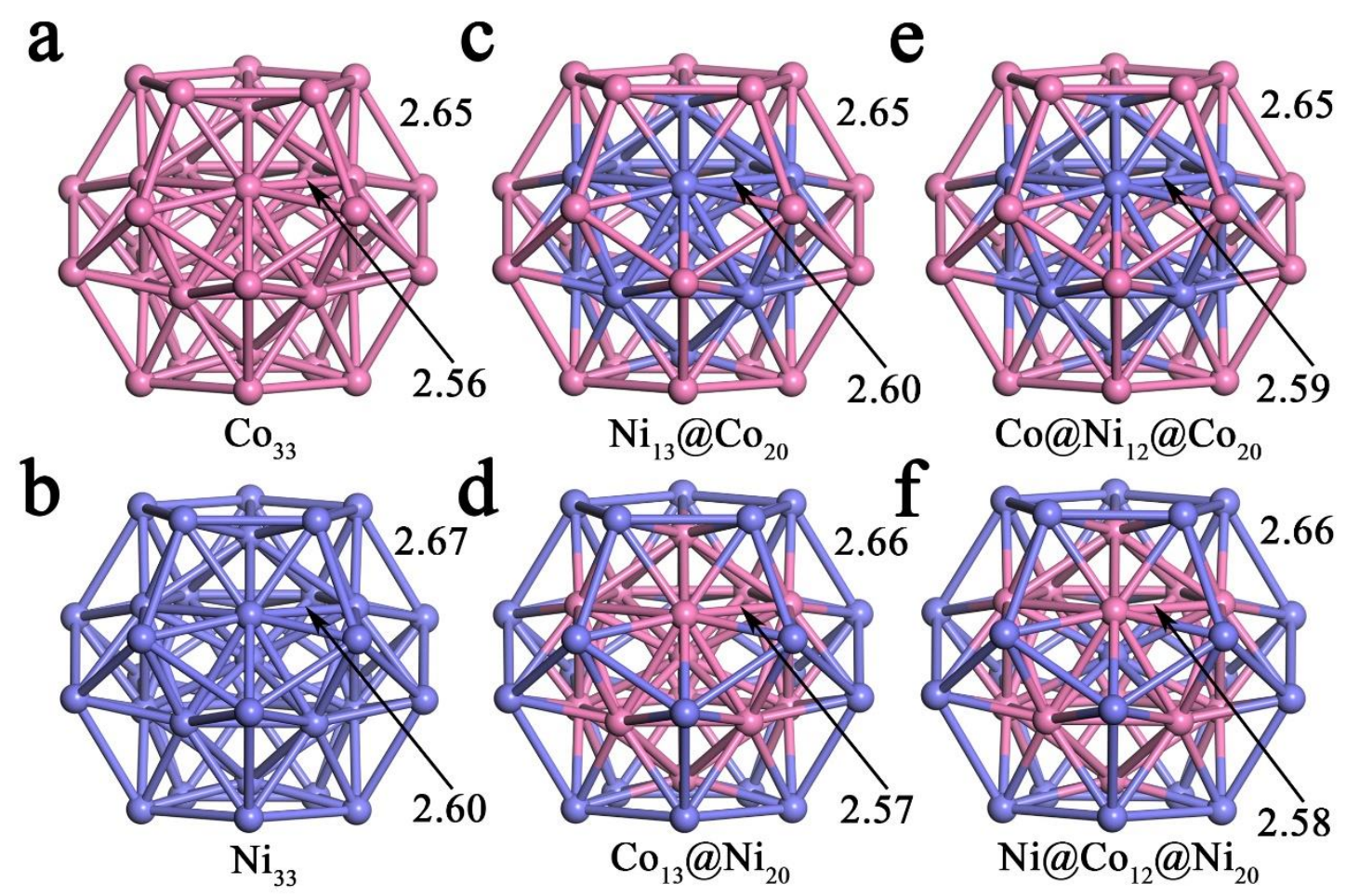

$$
\mathrm{Ni}_{13} @ \mathrm{Co}_{20}
$$

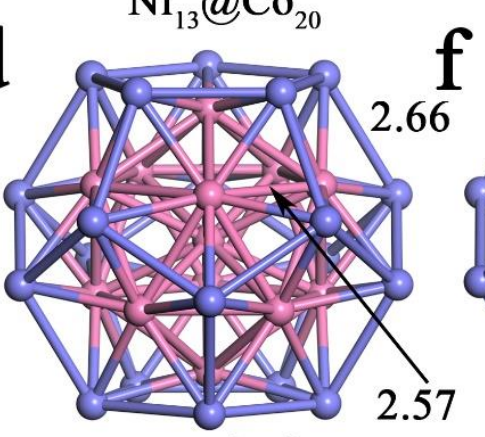

$\mathrm{Co} @ \mathrm{Ni}_{12} @ \mathrm{Co}_{20}$

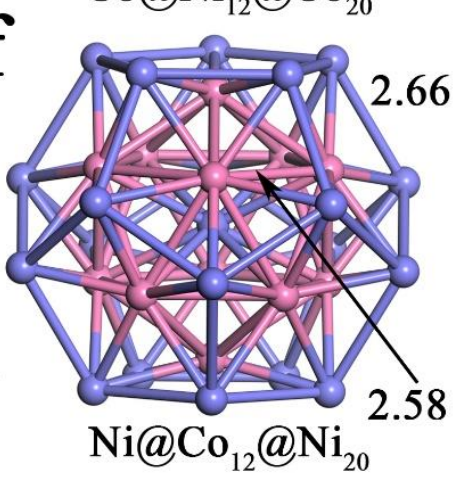

Figure S2. Representative optimized structures of 33-atoms monometallic and 
bimetallic Co-Ni core-shell nanoclusters. Magenta and violet spheres represent Co and $\mathrm{Ni}$ atoms, respectively. The bond lengths are displayed in angstroms.

The 33-atoms monometallic and bimetallic heteronuclear Co-Ni nanoclusters built by adsorbing $\mathrm{Co}$ or $\mathrm{Ni}$ atoms on 20 (111)-like surfaces of 13-atoms nanoclusters were displayed a dodecahedral geometrical structure, corresponding to the lowest energy. (Figure S2) These dodecahedral geometrical structures possess 1 atom at the center, 12 atoms in the inner shell, and 20 atoms in the surface shell which can be built by adding 20 atoms on the surface of icosahedral 13-atoms $\mathrm{Co}-\mathrm{Ni}$ nanoclusters. For monometallic $\mathrm{Co}_{33}$ and $\mathrm{Ni}_{33}$, the distance between the central atom and the adjacent 12 identical inner shell atoms are 2.43 and $2.47 \AA$, respectively, which are all shorter than the adjoin interatomic distance on the inner shell -2.56 and $2.60 \AA$. In particular, adjoin interatomic distance on the surface shell, 2.65 and $2.67 \AA$, are displayed longest distance in $\mathrm{Co}_{33}$ and $\mathrm{Ni}_{33}$.

$\mathrm{Ni}_{13} @ \mathrm{Co}_{20}$ and $\mathrm{Co}_{13} @ \mathrm{Ni}_{20}$ are displayed a similar dodecahedral geometrical structure swapping the 13 inner core atoms with each other in monometallic 33-atoms dodecahedral particles (see Figure S2c, d). The distance between the central atom and the adjacent 12 identical inner shell atoms were 2.47 and $2.44 \AA$, displayed in $\mathrm{Ni}_{13} @ \mathrm{Co}_{20}$ and $\mathrm{Co}_{13} @ \mathrm{Ni}_{20}$, which is $0.04 \AA$ longer than $\mathrm{Co}_{33}$ and $0.03 \AA$ shorter than $\mathrm{Ni}_{33}$, respectively. Adjoin interatomic distance on the inner shell in $\mathrm{Ni}_{13} @ \mathrm{Co}_{20}$ and $\mathrm{Co}_{13} @ \mathrm{Ni}_{20}$ are about 2.60 and $2.57 \AA$, which are all shorter than the adjoin interatomic distance on the surface shell-2.65 and $2.66 \AA$, and the interatomic distances between the center atom and surface shell atoms are 3.71 and $3.73 \AA$ in $\mathrm{Ni}_{13} @ \mathrm{Co}_{20}$ and $\mathrm{Co}_{13} @ \mathrm{Ni}_{20}$ as displayed in Table S1. Interestingly, these findings suggest that two bimetallic core-shell clusters $\mathrm{Ni}_{13} @ \mathrm{Co}_{20}$ and $\mathrm{Co}_{13} @ \mathrm{Ni}_{20}$, in different configurations are similar. Furthermore, we found that the icosahedron $\mathrm{Ni}_{13}$ and $\mathrm{Co}_{13}$, which are inside the 33-atoms dodecahedron $\mathrm{Ni}_{13} @ \mathrm{Co}_{20}$ and $\mathrm{Co}_{13} @ \mathrm{Ni}_{20}$, were elongated by the 20 atoms on the surface shell compared with their corresponding 13-atoms system. 
Compared to the bimetallic Co-Ni nanoclusters $\mathrm{Ni}_{13} @ \mathrm{Co}_{20}$ and $\mathrm{Co}_{13} @ \mathrm{Ni}_{20}$, the threelayer core-shell system can be considered to be replaced core atoms with each other in bimetallic 33-atoms dodecahedral Co-Ni nanoclusters (see Figure S2e, f). The distance between the central atom and the adjacent 12 identical inner shell atoms were both 2.46 A, displayedin $\mathrm{Co} @ \mathrm{Ni}_{12} @ \mathrm{Co}_{20}$ and $\mathrm{Ni} @ \mathrm{Co}_{12} @ \mathrm{Ni}_{20}$, which is $0.01 \AA$ shorter than $\mathrm{Ni}_{13} @ \mathrm{Co}_{20}$ and $0.02 \AA$ A longer than $\mathrm{Co}_{13} @ \mathrm{Ni}_{20}$ respectively. Adjoin interatomic distance on the inner shellin $\mathrm{Co} @ \mathrm{Ni}_{12} @ \mathrm{Co}_{20}$ and $\mathrm{Ni} @ \mathrm{Co}_{12} @ \mathrm{Ni}_{20}$ are about 2.59 and $2.58 \AA$. Interestingly, adjoin interatomic distances on the surface shell are the same with bimetallic $\mathrm{Co}-\mathrm{Ni}$ Nanoclusters, and the interatomic distances between the center atom and surface shell atoms are 3.71 and 3.72 A in $\mathrm{Co} @ \mathrm{Ni}_{12} @ \mathrm{Co}_{20}$ and $\mathrm{Ni} @ \mathrm{Co}_{12} @ \mathrm{Ni}_{20}$ as displayed in Table S1. In a word, three-layer bimetallic heteronuclear $\mathrm{Co}-\mathrm{Ni}$ nanoclusters are of negligible difference from their corresponding two-layer bimetallic structures in the geometry. However, the icosahedron $\mathrm{Co} @ \mathrm{Ni}_{12}$ and $\mathrm{Ni} @ \mathrm{Co}_{12}$, which inside the 33-atoms dodecahedron Co@ $\mathrm{Ni}_{12} @ \mathrm{Co}_{20}$ and $\mathrm{Ni} @ \mathrm{Co}_{12} @ \mathrm{Ni}_{20}$, were also elongated by the 20 atoms on surface shell compared with their corresponding 13 -atoms system as existed in $\mathrm{Ni}_{13} @ \mathrm{Co}_{20}$ and $\mathrm{Co}_{13} @ \mathrm{Ni}_{20}$.

3. 55-atoms Co-Ni core-shell nanoclusters 

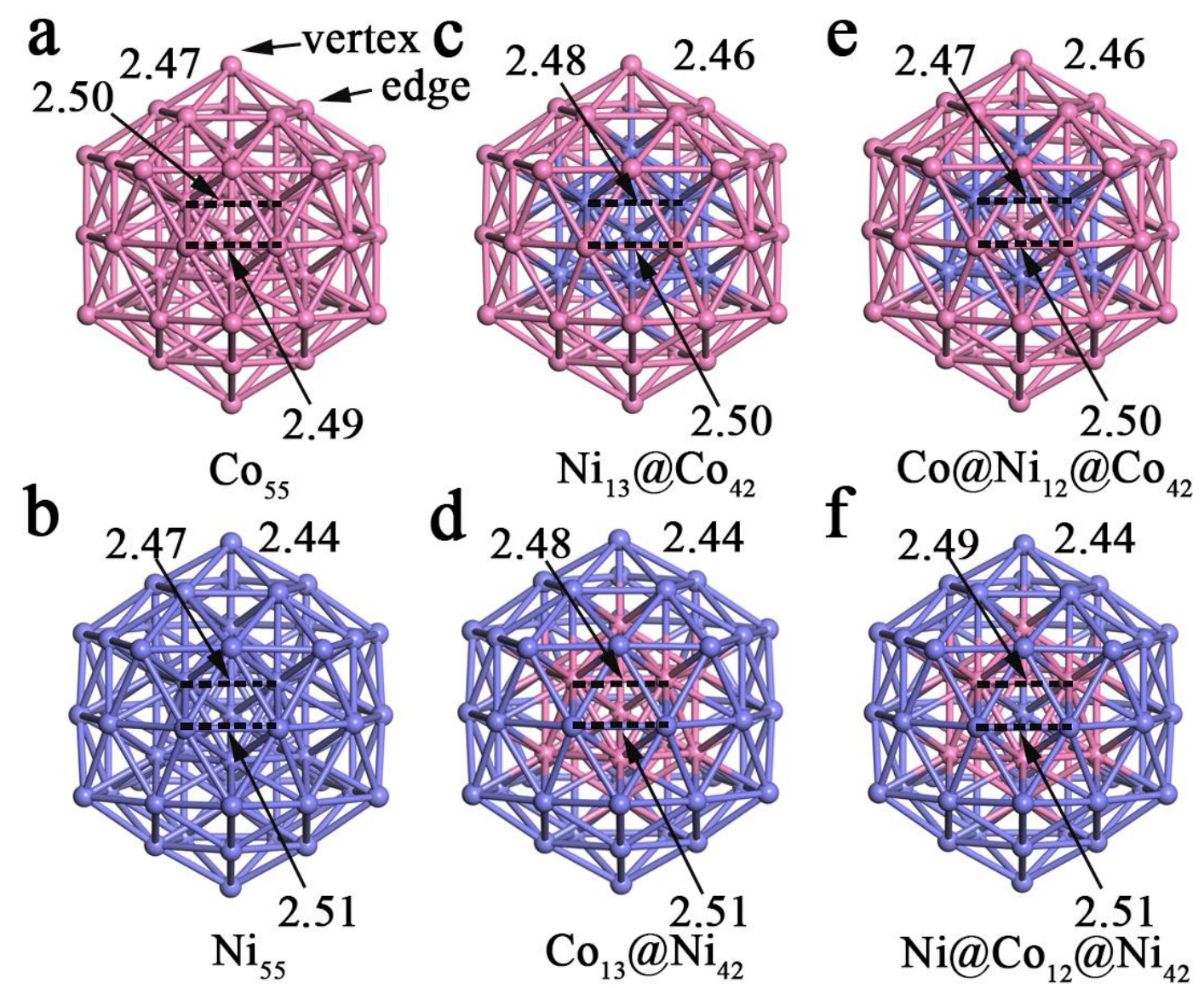

Figure S3. Representative optimized structures of 55-atoms monometallic and bimetallic Co-Ni core-shell nanoclusters. Magenta and violet spheres represent Co and $\mathrm{Ni}$ atoms, respectively. The bond lengths are displayed in angstroms.

Similarly, with spin-polarized DFT calculations, the 55-atoms monometallic and bimetallic Co-Ni nanoclusters built by adsorbing $\mathrm{Co}$ or $\mathrm{Ni}$ atoms at 12 vertices on the 13-atoms inner-icosahedral of 33-atoms nanoclusters were displayed an icosahedral geometrical structure, corresponding to the lowest energy. (Figure S3) Compared to 13atoms and 33-atoms Co-Ni Nanoclusters, the surface shell atoms of 55-atoms Co-Ni nanoclusters have two different environments vertex and edge atom displayed in Figure S3. Then, the surface shell atoms can be divided into two types of non-equivalent atoms related to the core atoms of the nanoclusters The first group has 12 identical atoms at the vertex (location in Co55 represented as "vertex atom" in Figure S3a) and the second group has 30 identical atoms at the edge (location in Co5s represented as "edge atom" in the Figure S3a). These 55-atoms $\mathrm{Co}-\mathrm{Ni}$ nanoclusters, which are displayed an 
icosahedral geometrical structure, possessing 1 atom at the center, 12 atoms in the inner shell, and 42 atoms in the surface shell. It can be constructed by adding 42 atoms on the surface of 13-atoms icosahedral Co-Ni clusters or adding 22 atoms on the surface of 33-atoms dodecahedral Co-Ni nanoclusters.

For monometallic $\mathrm{Co}-\mathrm{Ni}$ nanoclusters $\mathrm{Co}_{55}, \mathrm{Ni}_{55}$, the distance between the core atoms of the inner shell and the 12 neighboring are 2.38, $2.35 \AA$ respectively. Adjoin interatomic distance on the inner shell in $\mathrm{Co}_{55}$ and $\mathrm{Ni}_{55}$ are about 2.50 and $2.47 \AA$, which are both longer than the distance between inner shell atoms and vertex or edge atoms as displayed in Table $\mathrm{S} 1$. With a coordination number of 6, the vertex atoms in $\mathrm{Co}_{55}$ are $4.70 \AA$ away from the central atom, while the other group of 30 identical atoms at the edge, which with a coordination number of 8 (represented as "edge atom" in the Fig S3a), are $4.03 \AA$ away from the central atom. In addition, for Co5s two adjacent edge atoms and two adjacent vertex edge atoms, the surface Co-Co bond lengths are about 2.49 and $2.47 \AA$, respectively. The same describe with $\mathrm{Ni}_{55}$.

For two-layer bimetallic Co-Ni nanoclusters $\mathrm{Ni}_{13} @ \mathrm{Co}_{42}$ and $\mathrm{Co}_{13} @ \mathrm{Ni}_{42}$ are displayed a similar dodecahedral geometrical structure, swapping the 13 inner core atoms with each other in monometallic 55-atoms dodecahedral particles (see Figure S3c, d). Compared with corresponding $\mathrm{Co}_{55}$ and $\mathrm{Ni}_{55}$, the inner shells of $\mathrm{Ni}_{13} @ \mathrm{Co}_{42}$ and $\mathrm{Co}_{13} @ \mathrm{Ni}_{42}$ were displayed negligible changes, in which the geometrical structures have no notable variations observed. For $\mathrm{Ni}_{13} @ \mathrm{Co}_{42}$, the distance between the central Ni atom and the 12 same $\mathrm{Ni}$ atoms in the inner shell is $2.36 \AA$, and the length of the CoCo bond in the inner shell is about $2.48 \AA$, which is shorter than that of the Co55 by $\sim 0.02 \AA$. The vertex atoms in $\mathrm{Ni}_{13} @ \mathrm{Co}_{42}$ are $4.67 \AA$ away from the central atom, while the edge atoms are $4.04 \AA$ away from the central atom. The inner shell Co-Co bond length between two adjacent atoms is about $2.48 \AA$, which is longer than that surface edge atoms Co-Co distance by $\sim 0.02 \AA$, and the surface distance between two adjacent vertex and edge atoms is $2.46 \AA$, the same description with $\mathrm{Co}_{13} @ \mathrm{Ni}_{42}$ as shown in Table S1. Interestingly, two bimetallic Co-Ni nanoclusters $\mathrm{Ni}_{13} @ \mathrm{Co}_{42}$ and $\mathrm{Co}_{13} @ \mathrm{Ni}_{42}$ 
in different arrangements have almost the same atomic distance data.

Based on the two-layer bimetallic Co-Ni nanoclusters $\mathrm{Ni}_{13} @ \mathrm{Co}_{42}$ and $\mathrm{Co}_{13} @ \mathrm{Ni}_{42}$, three-layer structures, Co@Ni ${ }_{12} @ \mathrm{Co}_{42}$ and $\mathrm{Ni} @ \mathrm{Co}_{12} @ \mathrm{Ni}_{42}$, can be further modeled by exchanging center atoms with each other (see Figure S3e, f). It is of negligible difference between two-layer bimetallic and three-layer heteronuclear bimetallic $\mathrm{Co}-\mathrm{Ni}$ nanoclusters that the interatomic distances of $\mathrm{Co}-\mathrm{Co}, \mathrm{Ni}-\mathrm{Ni}$, and $\mathrm{Co}-\mathrm{Ni}$ are even less than $0.01 \AA$.

Table S1. Optimized structure parameters of the 13-33- and 55-atoms monometallic and bimetallic Co-Ni core-shell nanoclusters, as a schematic sketch in Figure S1 and S2. All values of the bond length are given in angstrom $(\AA)$.

\begin{tabular}{|c|c|c|c|c|c|}
\hline Sites & S-S(ve,ee) & $\mathrm{I}-\mathrm{S}(\mathrm{v}, \mathrm{e})$ & I-I & $\mathrm{C}-\mathrm{I}$ & $\mathrm{C}-\mathrm{S}(\mathrm{v}, \mathrm{e})$ \\
\hline $\mathrm{Co}_{13}$ & 2.42 & - & - & - & 2.30 \\
\hline $\mathrm{Ni}_{13}$ & 2.44 & - & - & - & 2.32 \\
\hline $\mathrm{Ni@C_{12 }}$ & 2.42 & - & - & - & 2.30 \\
\hline $\mathrm{Co} @ \mathrm{Ni}_{12}$ & 2.44 & - & - & - & 2.32 \\
\hline $\mathrm{Co}_{33}$ & 2.65 & 2.31 & 2.56 & 2.43 & 3.71 \\
\hline $\mathrm{Ni}_{33}$ & 2.67 & 2.32 & 2.60 & 2.47 & 3.74 \\
\hline $\mathrm{Ni}_{13} @ \mathrm{Co}_{20}$ & 2.65 & 2.30 & 2.60 & 2.47 & 3.71 \\
\hline $\mathrm{Co}_{13} @ \mathrm{Ni}_{20}$ & 2.66 & 2.32 & 2.57 & 2.44 & 3.73 \\
\hline 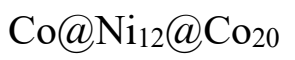 & 2.65 & 2.31 & 2.59 & 2.46 & 3.71 \\
\hline $\mathrm{Ni@Co}{ }_{12} @ \mathrm{Ni}_{20}$ & 2.66 & 2.32 & 2.58 & 2.46 & 3.72 \\
\hline Co55 & $2.47,2.49$ & $2.33,2.36$ & 2.50 & 2.38 & $4.70,4.03$ \\
\hline $\mathrm{Ni}_{55}$ & $2.44,2.51$ & $2.29,2.40$ & 2.47 & 2.35 & $4.64,4.06$ \\
\hline $\mathrm{Ni}_{13} @ \mathrm{Co}_{42}$ & $2.46,2.50$ & $2.32,2.38$ & 2.48 & 2.36 & $4.67,4.04$ \\
\hline $\mathrm{Co}_{13} @ \mathrm{Ni}_{42}$ & $2.44,2.51$ & $2.28,2.40$ & 2.48 & 2.36 & $4.64,4.06$ \\
\hline 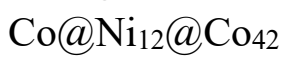 & $2.46,2.50$ & $2.34,2.38$ & 2.47 & 2.35 & $4.68,4.04$ \\
\hline $\mathrm{Ni@Co}{ }_{12} @ \mathrm{Ni}_{42}$ & $2.44,2.51$ & $2.27,2.40$ & 2.49 & 2.36 & $4.64,4.06$ \\
\hline
\end{tabular}

Note that S-S, the distance of nearest-neighbor on the surface-shell; (2) I-S, the distance between middle shell atom and its nearest-neighbor one from the surface-shell; (3) I-I, the distance of nearestneighbor on the inner shell; (4) C-I, the distance between the core atom and middle shell atoms, and (5) C-S, the distance between the core atom and surface-shell atoms.

Table S2. The cohesive energy of the 13- and 55-atoms monometallic and bimetallic Co-Ni core-shell nanoclusters and the foundational information of $\mathrm{Co}, \mathrm{Ni}$.

\begin{tabular}{ccc}
\hline Nanoparticle & $\mathrm{E}_{\text {total }}(\mathrm{eV})$ & $\Delta \mathrm{E}(\mathrm{eV})$ \\
\hline
\end{tabular}




\begin{tabular}{|c|c|c|}
\hline $\mathrm{Co}_{13}$ & -67.09536517 & -3.519457716 \\
\hline $\mathrm{Ni}_{13}$ & -49.92385286 & -3.486271874 \\
\hline 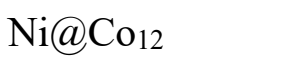 & -51.91461042 & -3.540353246 \\
\hline $\mathrm{Co} @ \mathrm{Ni}_{12}$ & -64.80702514 & -3.442485385 \\
\hline $\mathrm{Co}_{33}$ & -190.2894001 & -4.124621238 \\
\hline $\mathrm{Ni}_{33}$ & -140.1012015 & -3.891466455 \\
\hline $\mathrm{Ni}_{13} @ \mathrm{Co}_{20}$ & -162.9074197 & -4.075288328 \\
\hline $\mathrm{Co}_{13} @ \mathrm{Ni}_{20}$ & -168.1124673 & -3.959868618 \\
\hline $\mathrm{Co} @ \mathrm{Ni}_{12} @ \mathrm{Co}_{20}$ & -169.2618989 & -3.955678675 \\
\hline $\mathrm{Ni@Co}{ }_{12} @ \mathrm{Ni}_{20}$ & -161.3447238 & -4.066955111 \\
\hline Co55 & -331.8413366 & -4.391754627 \\
\hline $\mathrm{Ni}_{55}$ & -249.8686900 & -4.189042591 \\
\hline $\mathrm{Ni}_{13} @ \mathrm{Co} 42$ & -272.6302020 & -4.298522875 \\
\hline $\mathrm{Co}_{13} @ \mathrm{Ni}_{42}$ & -308.3245820 & -4.268542659 \\
\hline $\mathrm{Co@Ni} 12 @ \mathrm{Co}_{42}$ & -309.8582922 & -4.273015577 \\
\hline 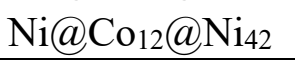 & -271.1891057 & -4.295733847 \\
\hline Nanoparticle & $\mathrm{E}_{\text {total }}(\mathrm{eV})$ & Bond length $(\AA)$ \\
\hline $\mathrm{Co}$ & -1.64172422 & 1 \\
\hline $\mathrm{Ni}$ & -0.35402450 & 1 \\
\hline $\mathrm{Co}-\mathrm{Co}$ & -6.73426612 & 1.96 \\
\hline $\mathrm{Ni}-\mathrm{Ni}$ & -4.21157571 & 2.08 \\
\hline $\mathrm{Co}-\mathrm{Ni}$ & -5.39773500 & 2.06 \\
\hline
\end{tabular}

\section{B. Charge transfer of the Co-Ni nanoclusters}

Table S3 Bader charges of the 13-atoms 33-atoms and 55-atoms monometallic and bimetallic Co-Ni core-shell nanoclusters

\begin{tabular}{lccc}
\hline $\begin{array}{c}\text { Nanoparticle net } \\
\text { charge }\end{array}$ & Inner core & Middle shell & Surface shell \\
\hline $\mathrm{Co} 13$ & +0.10 & - & -0.10 \\
$\mathrm{Ni} 13$ & +0.09 & - & -0.09 \\
$\mathrm{Ni} @ \mathrm{Co}_{12}$ & -0.09 & - & 0.09 \\
$\mathrm{Co} @ \mathrm{Ni}_{12}$ & +0.26 & - & -0.26 \\
$\mathrm{Co} 33$ & +0.02 & +0.47 & -0.49 \\
$\mathrm{Ni} 33$ & +0.03 & +0.47 & -0.50 \\
$\mathrm{Ni}$ & -0.02 & -0.97 & +0.99 \\
$\mathrm{Co} 13 @ \mathrm{Co}_{20}$ & +0.02 & +1.99 & -2.01 \\
$\mathrm{Co} @ \mathrm{Ni}_{12} @ \mathrm{Co}_{20}$ & +0.16 & -1.08 & +0.92 \\
$\mathrm{Ni@Co} \mathrm{Co}_{12} @ \mathrm{Ni}_{20}$ & -0.16 & +2.19 & -2.03 \\
$\mathrm{Co} 55$ & -0.13 & +0.70 & -0.57
\end{tabular}




\begin{tabular}{lccc}
$\mathrm{Ni}{ }_{55}$ & -0.14 & +0.82 & -0.68 \\
$\mathrm{Ni} 13 @ \mathrm{Co}_{42}$ & -0.14 & -0.52 & +0.66 \\
$\mathrm{Co} 13 @ \mathrm{Ni}_{42}$ & -0.20 & +2.03 & -1.83 \\
$\mathrm{Co} @ \mathrm{Ni}_{12} @ \mathrm{Co}_{42}$ & +0.03 & -0.70 & +0.67 \\
$\mathrm{Ni} @ \mathrm{Co}_{12} @ \mathrm{Ni}_{42}$ & -0.32 & +2.19 & -1.87 \\
\hline
\end{tabular}

\section{HER performance of the Co-Ni nanoclusters}

Table S4. The adsorption energy of $H$ species $\left(\triangle E_{H^{*}}\right)$, the relevant contributions to the free energy (EZPE and $\left.\Delta \mathrm{E}_{\mathrm{ZPE}}\right)$, and the free energy of adsorbed $\mathrm{H}\left(\triangle \mathrm{G}_{\mathrm{H}^{*}}\right)$ on different monometallic and bimetallic Co-Ni core-shell nanoclusters

\begin{tabular}{|c|c|c|c|c|}
\hline Nanoparticle & $\Delta \mathrm{E}_{\mathrm{H}^{*} / \mathrm{eV}}$ & $\mathrm{E}_{\mathrm{ZPE}} / \mathrm{eV}$ & $\Delta \mathrm{E}_{\mathrm{ZPE}} / \mathrm{eV}$ & $\Delta \mathrm{G}_{\mathrm{H}^{*} / \mathrm{eV}}$ \\
\hline $\mathrm{Co}_{13}$ & -0.74171928 & 0.152485366 & 0.017485366 & -0.39 \\
\hline $\mathrm{Ni}_{13}$ & -0.33376613 & 0.152570232 & 0.017570232 & 0.02 \\
\hline $\mathrm{Ni} @ \mathrm{Co}_{12}$ & -0.78789618 & 0.148505956 & 0.013505956 & -0.44 \\
\hline $\mathrm{Co} @ \mathrm{Ni}_{12}$ & -0.3395998 & 0.152184944 & 0.017184944 & 0.01 \\
\hline $\mathrm{Co}_{33}$ & -0.12161182 & 0.165150817 & 0.030150817 & 0.24 \\
\hline $\mathrm{Ni}_{33}$ & 0.13646185 & 0.168343187 & 0.033343187 & 0.50 \\
\hline $\mathrm{Ni}_{13} @ \mathrm{Co}_{20}$ & 0.08291456 & 0.163730217 & 0.028730217 & 0.45 \\
\hline $\mathrm{Co}_{13} @ \mathrm{Ni}_{20}$ & 0.27045918 & 0.164913983 & 0.029913983 & 0.64 \\
\hline $\mathrm{Co} @ \mathrm{Ni}_{12} @ \mathrm{Co}_{20}$ & -0.01566895 & 0.165924588 & 0.030924588 & 0.35 \\
\hline Ni@Co12@Ni20 & 0.04281058 & 0.16510809 & 0.03010809 & 0.41 \\
\hline $\mathrm{Co}_{55}$ & 0.07470939 & 0.162873234 & 0.027873234 & 0.44 \\
\hline $\mathrm{Ni}_{55}$ & 0.59787493 & 0.168105314 & 0.033105314 & 0.96 \\
\hline $\mathrm{Ni}_{13} @ \mathrm{Co}_{42}$ & 0.32127687 & 0.163215382 & 0.028215382 & 0.68 \\
\hline $\mathrm{Co}_{13} @ \mathrm{Ni}_{42}$ & 0.354949 & 0.16761116 & 0.03261116 & 0.72 \\
\hline $\mathrm{Co} @ \mathrm{Ni}_{12} @ \mathrm{Co}_{42}$ & 0.38262372 & 0.163512221 & 0.028512221 & 0.75 \\
\hline $\mathrm{Ni@Co} 12 @ \mathrm{Ni}_{42}$ & 0.29417206 & 0.168303885 & 0.033303885 & 0.66 \\
\hline
\end{tabular}

In this work, three possible adsorption sites for the $\mathrm{H}$ atom on the monometallic and bimetallic Co-Ni core-shell nanoclusters were considered, including the top, bridge, and hollow sites. The results show that the most stable adsorption site of $\mathrm{H}$ atom on the 13-atoms nanoclusters is the hollow site, while the most stable adsorption site of $\mathrm{H}$ atom on the 33-atoms nanoclusters is the bridge site. More interestingly, in the 55-atoms system, the most stable adsorption site of $\mathrm{H}$ atom on the nanoclusters with Co surface shell is the hollow site, while the most stable adsorption site of $\mathrm{H}$ atom on the nanoclusters with Ni surface shell is the bridge site. Only the optimized geometry 
structures and adsorption energies of the most stable adsorption sites of $\mathrm{H}$ atom on $\mathrm{Co}$, Ni MNPs, and bimetallic Co-Ni nanoclusters are presented in Figure S4 and Table S4. The adsorption energy of $\mathrm{H}$ atom on nanoclusters was defined by the energy difference between a fully optimized $\mathrm{H}$ atom adsorbed nanoclusters and its corresponding isolated nanoclusters with free $\mathrm{H}$ atom, $\Delta \mathrm{E}_{\mathrm{H}^{*}}=\mathrm{E}_{\mathrm{H} / \mathrm{NC}}-\left(\mathrm{E}_{\mathrm{NC}}+\mathrm{E}_{\mathrm{H}}\right)$, where $\mathrm{E}_{\mathrm{H}^{*}}$ is the adsorption energy, $\mathrm{E}_{\mathrm{H} / \mathrm{NC}}$ means the total energy of the fully optimized $\mathrm{H}$ atom adsorbed nanoclusters.
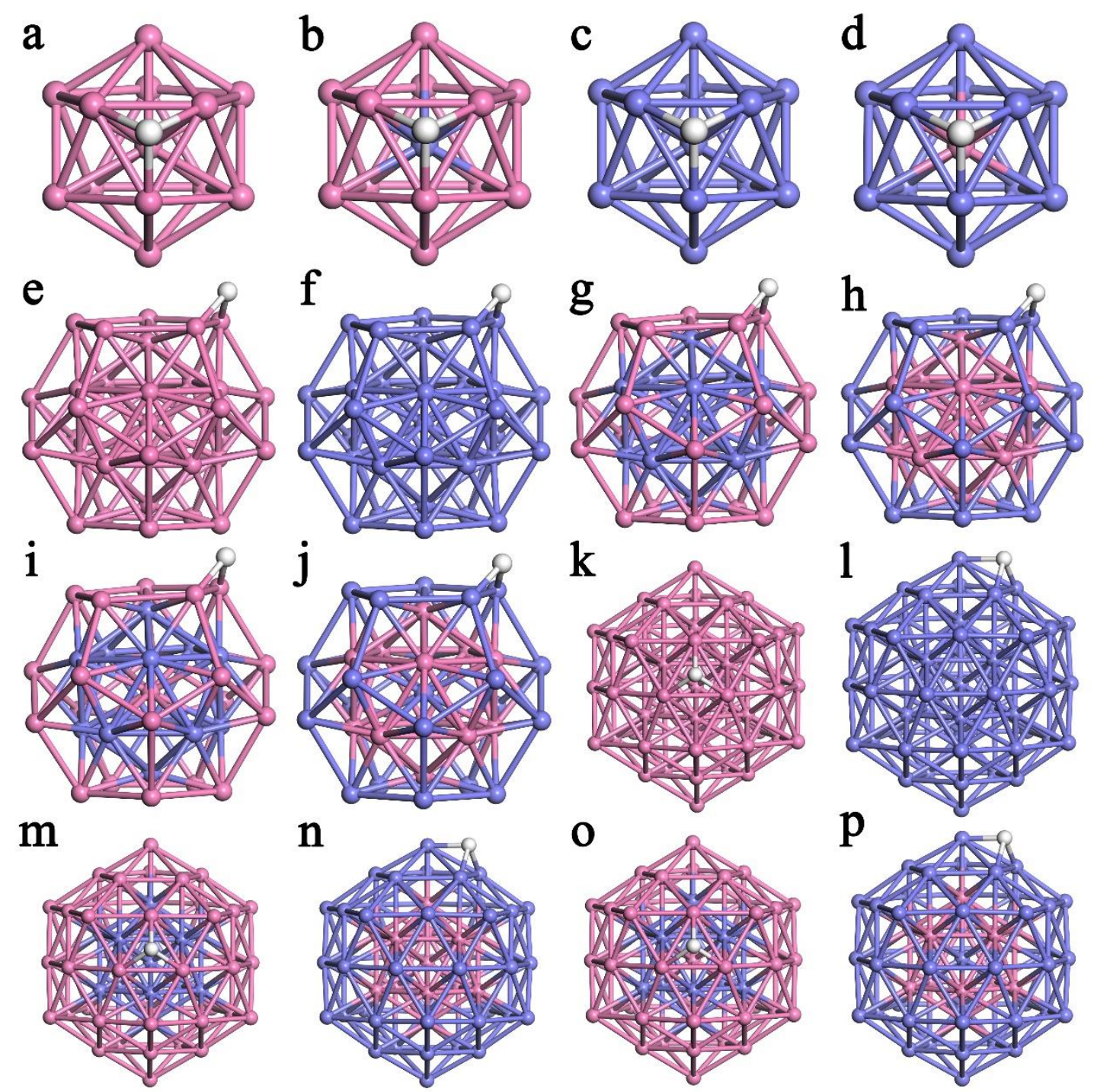

Figure S4. Schematic optimized geometry structures of the most stable adsorption sites of $\mathrm{H}$ atom adsorbed on 13/33/55-atoms monometallic and bimetallic Co-Ni core-shell nanoclusters. 